العـــــــد السابع والثلاثون

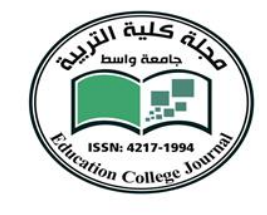

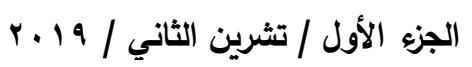

جامعة واسط مجلـــة كليــــة التربيــــة

\title{
تقنين اختبار كوبي للمواجهة وفق النظرية التقليدية لاى طلاب الجامعة
}

م.م. هبه محمدعلي المشهداني

جامعة واسط / كلية التربية للعلوم الانسانية

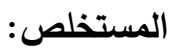

تمثل التربية منذ القدم مكانة خاصة في حياة المجتمعات والافراد، اذ تؤدي التربية دورا مهما

في المحافظة على تراث المجتمع، وانها اداة تقدم هذا التراث وتطويره واغنائه وعن طريق التربية يتم

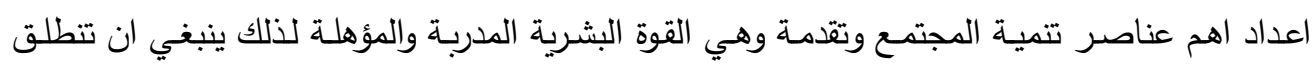
العملية التربوية من فلسفة المجتمع واهدافه وتتجه نحو المستقبل ساعية الى تحقيق تطلعاته.

ولا شك ان القدرات الانفعالية تعد من اهم الخصائص المهمة في الشخصية البشرية وقد ركز

علماء النفس جهودا كبيرة لدراستها ووضـع الاختبارات والمقاييس لقياسها. ومن اهم خصـائص التعلم وجود نوع من الاتصال الجيد بين الباحثين بحيث يستطيع الباحث ان يقارن بين نتائجه ونتائج زملائه الذين يتـاولون المشكلات نفسها بالدراسـة وفي علم النفس يستطيع الباحثون ان يحققوا هذا الاتصـال من خلال اجراء عملية التقنين ولذلك تتحدد اهداف البحث الحالي في الاتي:

- اتقنين اختبار كوبي cope للمواجهه لدى طلبة الجامعة.

ץ- تعرف الفروق بين طلبة الجامعة بحسب متغيرات (الجنس والتخصص والصف). ولتحقيق الهدف الاول من اهداف البحث الحسالي قامـة الباحثة بترجمة تعليمـات الاختبار وفقراتـه

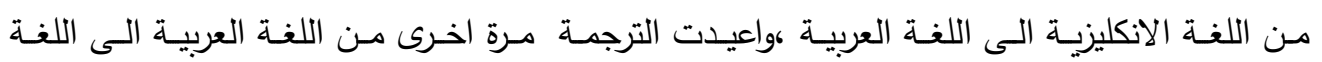
الانكليزيـة ،ثم عرضت على مجموعة من المتخصصين باللغة الانكليزيـة واجراء بعض التعديلات في ضوء ملاحظاتهم

ثم عـرض تعليمـات الاختبـار وفقراتـه على مجموعـة مـن الخبـراء المتخصصـين في العلـوم التربويـة والنفسية للتأكد مـن توافر الخصـائص المناسبة لهذه الفقرات وبدائلها مـن حيث الشـكل والمضـمون

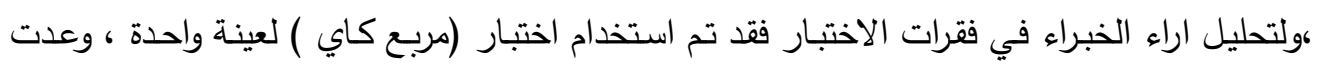
كل فقرة من فقرات المقيـاس صـالحة عندما تكون قيمـة (مربع كاي ) دالة عند مستوى (0. . • )وهي 
العـــــــد السابع والثلاثون

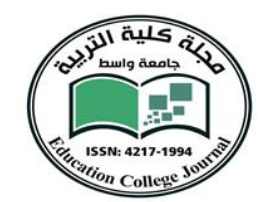

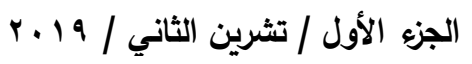

جامعة واسط

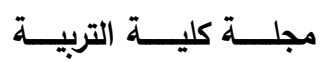

توازي نسبة ( •^^\%) مـن عدد الخبراء ،وقد عدت جميـع فقرات الاختبـار صـالحة منطقيـا لقيـاس مـا وضـت مـن اجل قياسـه ، وبعد ذلك عرضـت تعليمـات الاختبـار وفقراتـه على اختصـاص في اللغـة العربية للتاكد مـن سـلامة اللغـة، واجريـت بعض التعديلات اللغويـة في ضـوه تعديلاتهم ،ثم جهزت فقـرات الاختبـار للتطبيـق الاســطلاعي الـني يتضــن ( كـراس اســلة فقـرات الاختبار ،ورقــة اجابـة منفصلة، مفتاح الاجابة للمقياس).

تم تطبيق الاختبار على عينة استطلاعية قوامها ( (r) طالبا وطالبة اختيروا عشوائيا من طلبة جامعة واسط البط

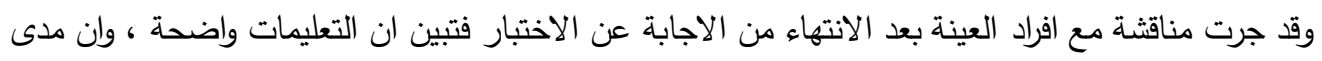
الوقت المستغرق للاجابة عن الاختبار بين (• (1 9 (1) دقيقة وبمتوسط قدره ( ع ( ) دقيقة.

ثم طبق الاختبار على عينة التحليل الاحصائي البالغ قوامها ( . . ب) طالبا وطالبة اختيروا بالطريقة العشوائية

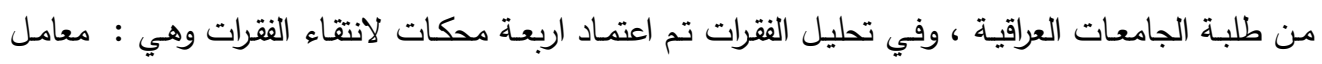
التمييز (• r, • ) فاكثر باستخدام اسلوب المجموعتين المتطرفتين في الدرجة الكلية ، دليل صدق الفقرة بالاعتماد على علاقة ارتباطية دالة بين درجة الفقرة وكل من الدرجة الكلية للاختبار باستخدام معامل الارتباط الثنائي

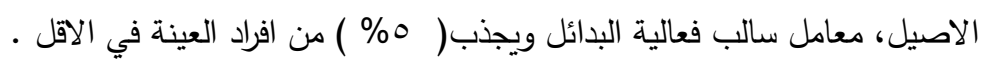

\section{استخرج صدق الاختبار بطربقتين هما :}

الصـدق الظـاهري: من خـلال عرض تعليمات الاختبار وفقراتـه على مجموعة من المتخصصين في العلوم التربوية والنفسية . صدق البناء : من خلال التحقق من وجود ارتباط بين درجة الفقرة والدرجة الكلية للاختبار ـ استخرج ثبات الاختبار:

- طريقة الفاكرونباخ :اذ بلغ معامل الثبات للاختبار ( 1 , • ) وتمثلت نتائج تحليل الاحصائي للفقرات في الاتي :

عدم وجود فروق ذات دلالة احصائية بين التفاعلات بين الجنس والتخصص. عدم وجود فروق ذات دلالة احصائية في التفاعلات بين الجنس والصف. وجود فروق ذات دلالة احصائة في التفاعلات بين والتخصص والصف. عدم وجود فروق ذات دلالة احصائية بين التفاعلات (الجنس والصف والتخصص). وفي ضوء نتائج البحث خرج الباحث ببعض الاستتتاجات والتوصيات والمقترحات. 


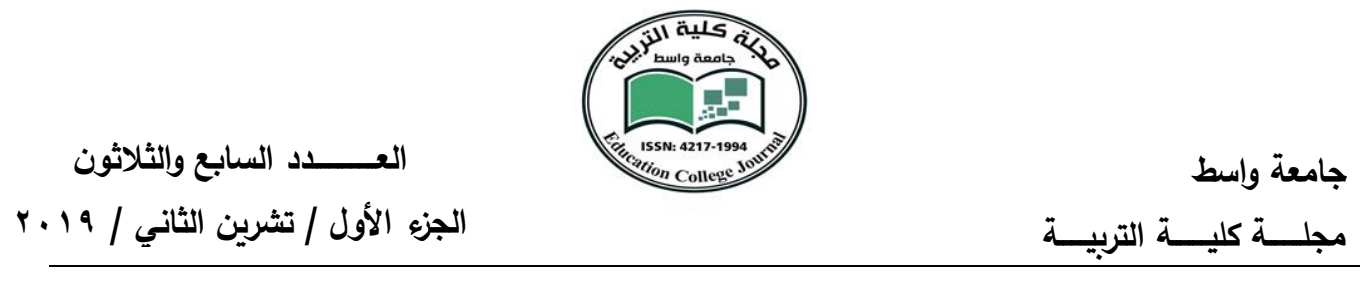

The standardization of the kobe test for confrontation in accordance with the traditional theory of university students

\section{Assistant Lecture. Heba Mohamed Ali Mashhadani}

Education has long been a special place in the lives of communities and individuals. Education plays an important role in preserving the heritage of society. It is a tool for the advancement, development and enrichment of this heritage. Through education, the most important elements of community development and progress are prepared. Of the philosophy and goals of the society and moving towards the future seeking to achieve its aspirations

There is no doubt that emotional capacity is one of the most important characteristics of the human personality and psychologists have concentrated great efforts to study and develop tests and measurements to measure them. One of the most important characteristics of learning is the existence of a kind of good communication between researchers so that the researcher can compare the results and the results of colleagues who deal with the same problems in the study and in psychology researchers can achieve this communication through the process of rationing and therefore determine the current research objectives in the following:

1-To qualify the Kobe test for university students.

2-Differences between university students according to variables (gender, specialization and grade)

In order to achieve the first objective of the current research, the researcher translated the test instructions and paragraphs from English to Arabic. The translation was re-translated from Arabic to English and then presented to a group of specialists in English and made some adjustments in the light of their observations.

The test instructions and their paragraphs were then presented to a group of experts in the educational and psychological sciences to ascertain the availability of the appropriate characteristics of these paragraphs and their alternatives in terms of form and content. In order to analyze the opinions of the experts in the test paragraphs, Is valid when the value of the square (kai) is a function at the level of (05.0) which is equivalent to (80\%) of the number of experts. All the test paragraphs have been validly validated to measure 
العـــــــد السابع والثلاثون

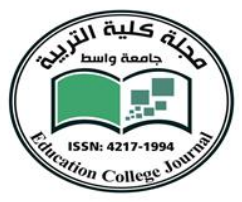

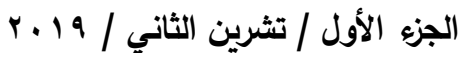

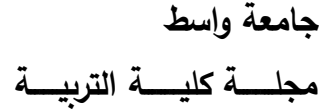

what was set for measurement. Then the test instructions and paragraphs were presented to specialists in Arabic language to ensure the safety of the language, and was conducted some And then prepared the test paragraphs for the exploratory application, which includes (the test question sheet, a separate answer sheet, the answer key for the test).

The test was carried out on a sample of 30 randomly selected students from Wasit University. The participants were interviewed after completing the test. The instructions were clear. The time taken to answer the test was between 10 - 19 minutes, (14) minutes.

The test was then applied to the sample of the statistical analysis of 300 students who were randomly selected from the Iraqi university students. In analyzing the paragraphs, four scales were selected for selecting the paragraphs: difficulty level (20.0-80.0), discrimination coefficient (20) (0) and more using the two extreme groups method in the total score, the evidence of the veracity of the paragraph based on a significant correlation between the degree of the paragraph and the total score of the test using the original binary correlation coefficient, negative coefficient of the alternatives and attracting at least $5 \%$ of the sample.

The validity of the test was extracted in two ways:

Virtual honesty: by presenting test instructions and paragraphs to a group of specialists in educational and psychological sciences.

Validation of construction: by verifying the existence of a correlation between the degree of the paragraph and the total score of the test.

Extract the test stability:

-Vaccronbach method: the stability coefficient of the test $(81,0($

The results of the statistical analysis of the paragraphs were as follows:

-There are no statistically significant differences between the interactions between sex and specialization.

-There are no statistically significant differences in interactions between sex and grade.

-There are significant differences in interactions between specialization and grade.

-There are no statistically significant differences between interactions (sex, grade, and specialization.)

- In the light of the results of the research came out with some conclusions, recommendations and suggestions. 
العـــــــد السابع وإلثلاثون

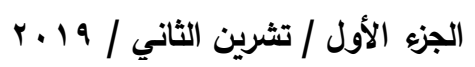

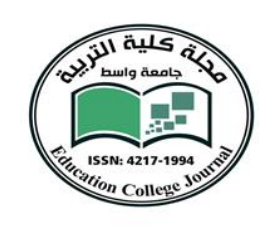

جامعة واسط

مجلـــة كليـــة التربيــة

research problem : مشكلة البحث

ان مشكلة تقنين الاختبارات النفسية تحتل مكانة خاصة في تاريخ علم النفس وما زالت تمثل المكان نفسه في علم النفس المعاصر ويرتبط بهذه المشكلة حاجة ماسة تتمثل في تزايد الاهتمام بالاختبارات والمقاييس النفسية في مختلف المجالات العلمية والتطبيقية ، واذا كانت الدول التي

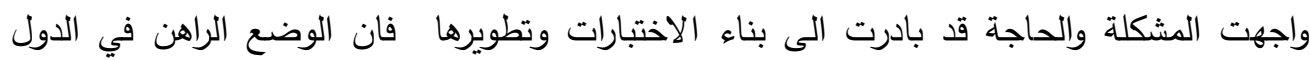

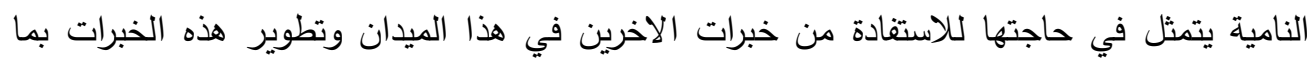

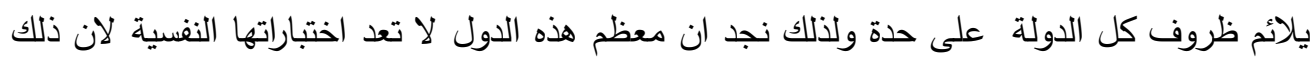

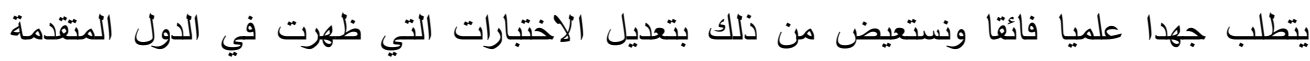

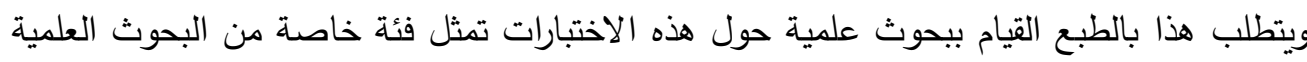

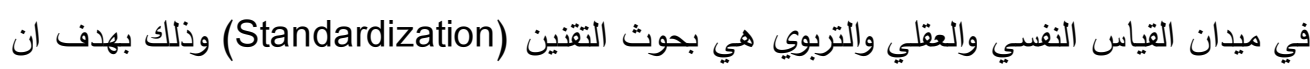
تصبح هذه الاختبارات اكثر ملاءمة للظروف الجديدة ( ابو حطب ، و 19VV : 19V ).

على الرغم من وجود بعض المقاييسالمعدة لقياس القدرات والاستعدادات لمراحل اخرى غير

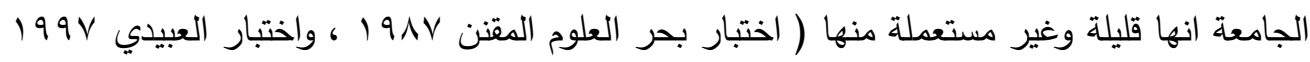

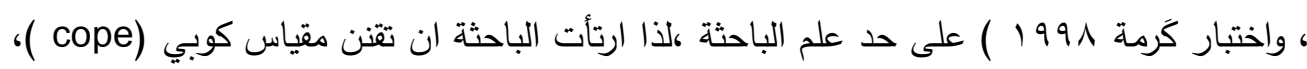

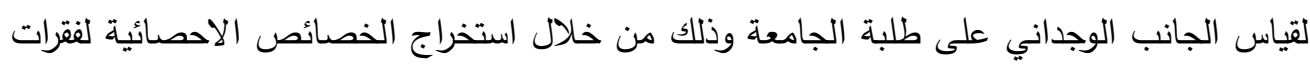

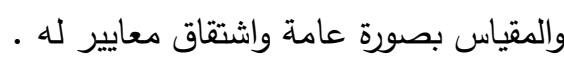

ومن هنا تنطلق مشكلة البحث الحالي المتمثلة بالحاجة الى مقاييس مقننة تستوعب الظروف المحلية

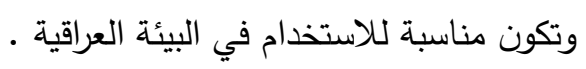

اهمية البحث : research importance

اعتمدت العلوم النفسية على منهج القياس والتكميم في دراسة الظواهر لان الارقام تسهل عملية

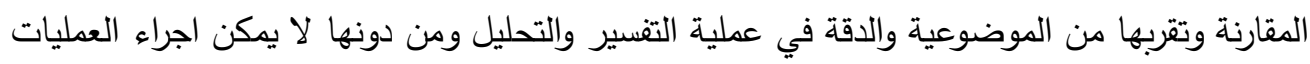
الرياضية والاحصائية التي تساعد على وصف الظاهرة وصفا دقيقا (Ghiselli etal,1981:23 ) ) فالظواهر النفسية ندرسها من خلال اختيار عينات من الافراد وهم يختلفون في كمية هذه الظواهر وما فالئ

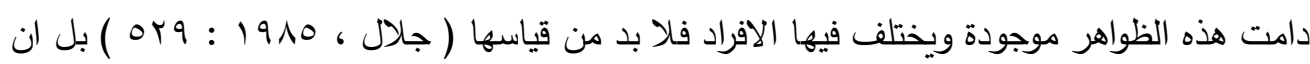


العـــــــد السابع والثلاثون

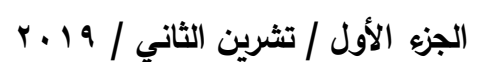

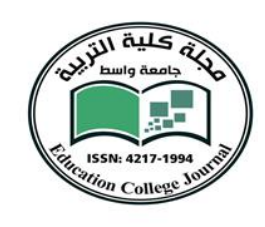

جامعة واسط

مجلـــة كليـــــة التربيــــة

ثورندايك ( E.L.Thorindike) يقول " ان كل ما يوجد يوجد بمقدار ، وان كل ما يوجد بمقدار يمكن

$$
\text { ان يقاس " (السيد ، } 1979 \text { : } 1979 \text { (1) ). }
$$

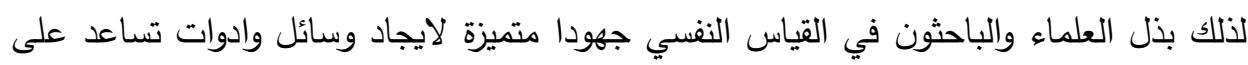
تكميم الظواهر النفسية لتقترب مما هو عليه في الظواهر الطبيعة التي تتسم بدقة ادوات قياسها وتكميم

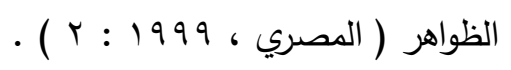

وقد تبرز اهية القياس في تصنيف الخصائص النفسية وتعرُف جوانبها والمتغيرات المتعلقة

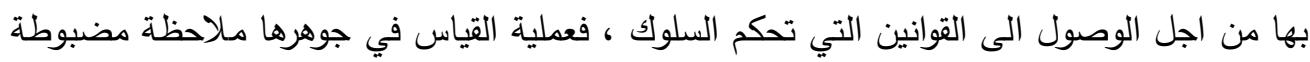

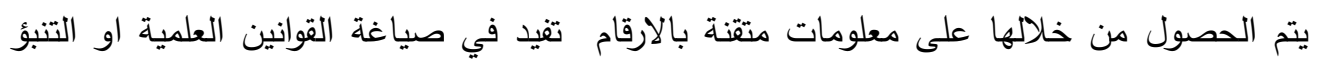

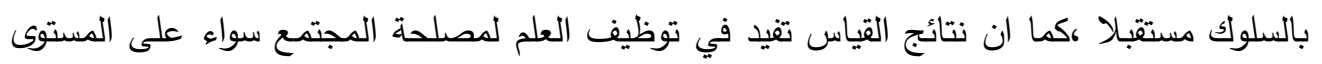

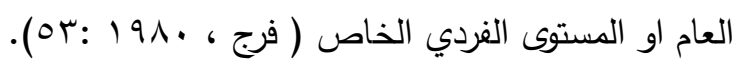

وتزداد اهمية القياس في علم النفس لان القرارات التي تتذذ تتعلق بالانسان ومستقبله

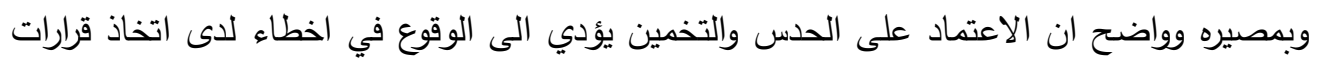

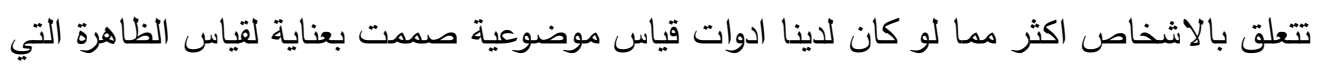

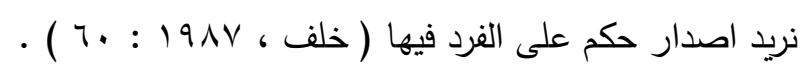

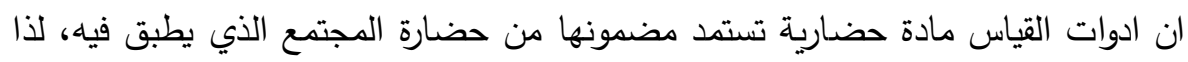

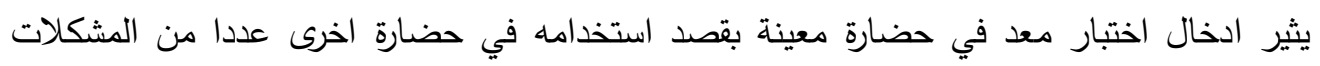

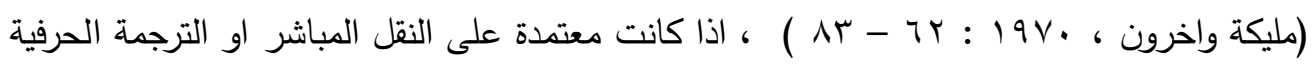

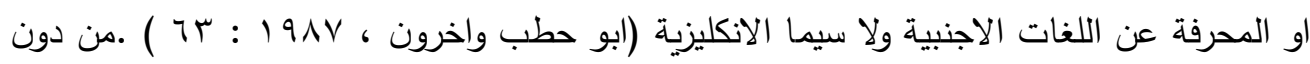

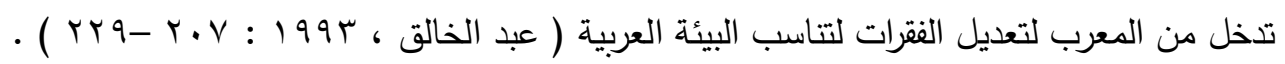

ومن اهم خصائص العلم وجود نوع من الاتصال الجيد بين الباحثين بحيث يستطيع الباحث

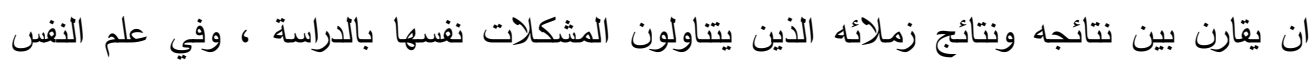

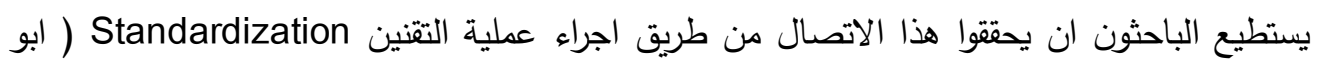

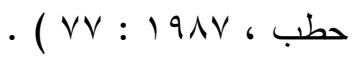


العـــــــد السابع والثلاثون

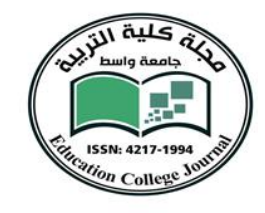

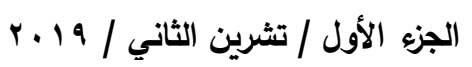

جامعة واسط

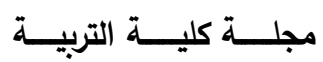

اذ ان عملية التقنين Standardization توفر للباحثين استخدام الاختبارات والمقاييس

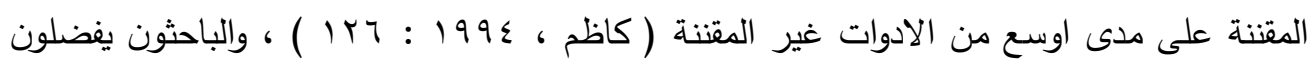
استخدام الاختبارات المقننة ، بل يبذلون جهدا كبيرا في سبيل تقنين اختباراتهم من اجل تحقيق ذلك الاتصال فيما بينهح ، ويؤكد هيلز Hills ان هناك ثلاثة اسباب رئيسة تدفع الباحثين الى استخدام الاختبارات المقننة : الإل

1- ان بعض الاختبارات المقننة قد صمم لقياس بعض جوانب التحصيل بهدف علاج نواحي الضعف بل لتوجيه الطلبة عن طريق وضعهم في صفوف متجانسة .

ץ- يوفر على الباحثين بدل الجهد والوقت لوضع اختبارات قد تحقق او لا تحقق الهدف الذي يسعون اليه ليه

r- تمكن الباحثين من اجراء مقارنة بين اداء طلبتهم و طلبة اخرين طبق الاختبار عليهم نفسه . ) .Hills , $1981: 1-3$ )

وفي مجال الجانب الوجداني تتيح عملية التقنين لما تتضمنه من صدق وتمييز وثبات واشتقاق معايير فرصاً اوسع لاستخدام المقاييس المقننة في البحوث ، او التصنيف ، او الانتقاء ، او

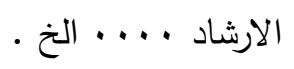

وعليه يعد طلبة الجامعة شريحة مهمة في المجتمع لانهم عمادة وقادة مستقبله في معظم مفاصل الحياة وميادينها ومركز طاقاته المنتجة القادرة على احداث التغير وبخاصة بعد اكمالهم

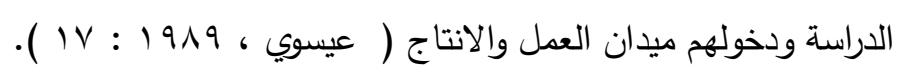

وتسعى كثير من الدول ولاسيما المتقدمة منها الى الاهتمام بثرواتها البشرية وذلك بالعمل على اكتشافهم ورعايتهم وتوفير البرامج الملائمة والوسائل اللازمة التي تساعد على نموهم واستثمار طاقاتهم على الوجه الاكمل اضافة الى اوضع انواع الادوات والمقاييس المساعدة على تشخيصهم ورته

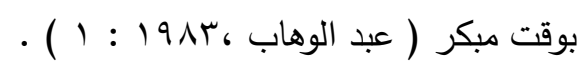

لذلك تعد المقاييس والاختبارات بانواعها المختلفة ولاسيما ما يقيس الجانب الوجداني منها وتقف كشاهد على مقدار التقدم العلمي في هذا المجال . 
العـــــــد السابع والثلاثون

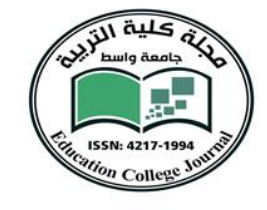

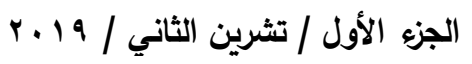

جامعة واسط

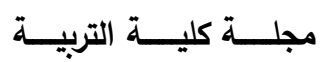

وتتضح اهمية البحث الحالي من خلال استعمال المقياس الذي ستوفره هذه الدراسة في

المجالات الاتية : 20 - 20

1 - يشير عبد الخالق الى ان احد الاستخدامات المهمة للمقاييس والاختبارات هو في البحوث

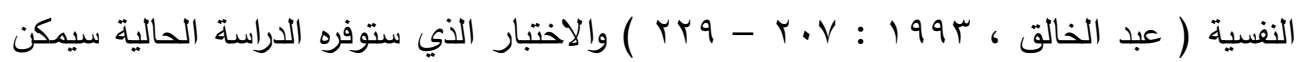
الباحثين من اجراء البحوث في ضوء ما ترتبط به القدرات العقلية مع المتغيرات النفسية بغية اثراء المعرفة عن قدرات الطلبة العراقيين.

ץ-ان المقاييس اكثر اقتصادا في الجهد واكثر قدرة على التنبؤ بالظاهرة وتحديد شروطها الأساسية مما يساعد المربين على تكوين صورة عن إمكانيات الطلبة وقدراتهم واستعدادتهم.

ب- التوجيه المهني والتربوي وتقديم المشورة للطلبة حول تعليمهم والمهن التي تتاسبهم بعد مدة التعليم الرسمي ، اذ تعد بيانات مقاييس الجانب الوجداني قيمة على وجه الخصوص ويمكن منع العديد من حالات سوء التوافق في الجوانب المهنية من معلم او مرشد مهتم بالبيانات الخاصة بتلك القدرات .

أهداف البحث : research goals

$$
\text { يهدف البحث الحالي الى : }
$$

ا-تقنين اختبار (cope) للمواجه على طلبة الجامعة لاعداد صورة عراقية له .

ץ- تعرف دلالة الفروق في للمواجه لاى طلبة الجامعة تبعا لمتغير (الجنس والمرحله، التخصص).

$$
\text { حدود البحث : حتصر البحث الحالي على : }
$$

الحد الموضوعي : تقنين اختبار ( cope) للمواجه لدى طلبة جامعة واسط للعلوم الانسانية . الحدود المكانية : جامعة واسط : الحدود البشرية : تم تطبيق هذه الدراسة على طلبة جامعة واسط المرحلة الاولى والثانية والثالثة والرابعة، للدراسة الصباحية وللتخصصين (الإنساني والعلمي ) .

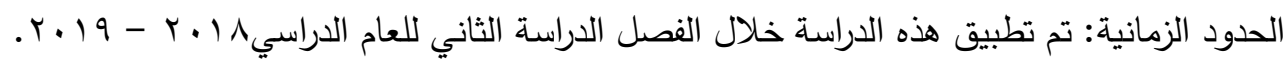


العـــــــد السابع وإلثلاثون

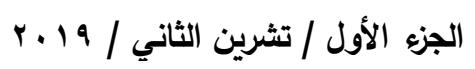

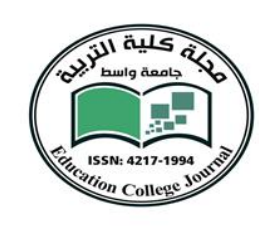

جامعة واسط

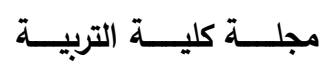

terminology : تحديد المصطلحات

: Standardization التقنين

عرفه هيلز (Hills,1981) بانه : عملية توحيد شروط اعداد الاختبار وتطبيقه على

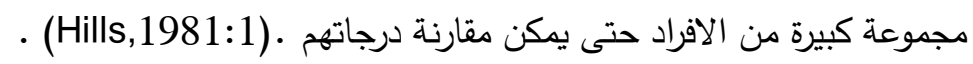

وعرفه جلال ( 0^19 ) بانه:(تحديد تعليمات اعطاء الاختبار وتحديد طرق تصحيح

الاجابات أي توحيد المواصفات الخاصة بالعينة وتحديدها)(جلال ، و91901 : (0).

كما عرفه عيسوي (910) (19) بانه ( رسم خطة شاملة وواضحة ومحدة لجميع خطوات

الاختبار واجراءاته وطريقة تطبيقه وتصحيحه وتفسير درجاته وتحديد ظروف المفحوصين

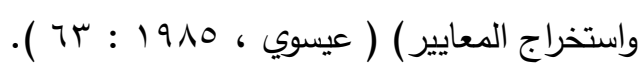

وعرفه الكبيسي ( 9 و ) ) بانه: ( تحديد إجراءات تطبيق المقياس والاجابة عنه وتحديد

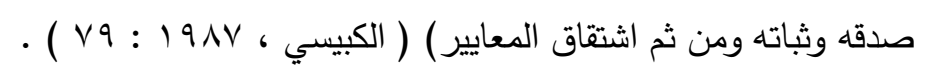

وعرفه علام ( . . . . ) بانه: ( ويقصد به ان يكون بناء الاختباروتصحيحه وتفسير نتائجه

او اداة القياس مستندا الى قواعد محددة بحيث تتوحد فيه وتحدد بدقة مواد الاختبار وطريقة

تطبيقه ، وتعليمات اجابته وطريقة تصحيحه او تسجيل درجاته ، وبذلك يصبح الموقف

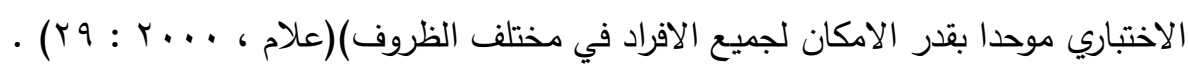

ومن خلال التعريفات السابقة يمكن تحديد جوانب الاتفاق في تلك التعريفات فيما ياتي:

- توحيد اجراءات تطبيق الاختبار وطريقة تصحيحه . .

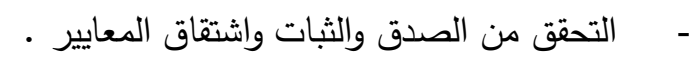

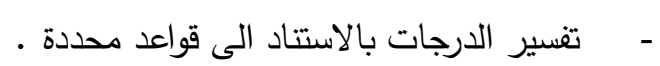

ومما تقدم يمكن تعريف التقنين نظرياً بانه : ضبط خطوات القياس واجراءاته وتتظيمها وتحديدها وطرق تصحيحه وتطبيقه وتفسير نتائجه ، بالثكل الذي يضمن وصف السلوك وتحديده

تحديدا دقيقا . تحون 
العـــــــد السابع والثلاثون

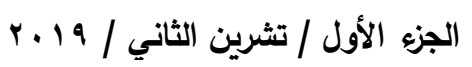

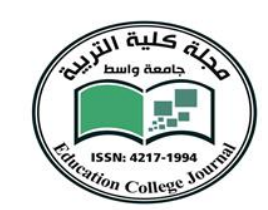

جامعة واسط

مجلــــة كليــــة التربيــــة

تعريف المواجه :

التعريف النظري

اعتمد الباحث تعريف ( cope 1989 (لاعتماد مقياسه

ان الناس مختلفون بتعاملهم مع الاشياء بطرق مختلفة ولكن انا مهتم في ما انت كبف تحاول التعامل

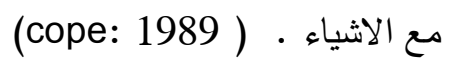

التعريف الإجرائي

يعرف إجرائيا بانه الدرجة التي يحصل عليها الفرد من خلال استجابته على فقرات قائمة أساليب

المواجهة . المجرة

theoretical framework : الاطار النظري

يعد الاطار النظري من المتطلبات الاساسية في بناء الاختبارات والمقاييس العقلية واعدادها

، لانه يوفر للباحث المفاهيم النظرية التي تستند اليها معظم اجراءات بناء الاختبارات ، ولا سيما

عندما يعتمد في بنائه على المنهج العقلي او المنطقي الذي يتطلب اشتقاق بعض المفاهيم او

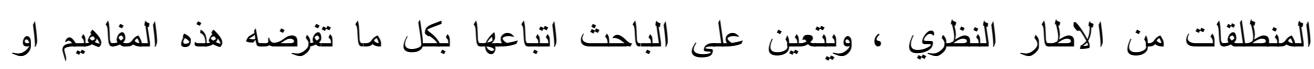

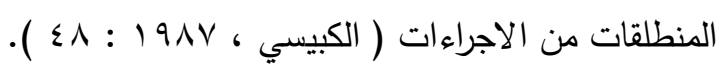

the nature of measurement is its cocept طبيعة القياس ومفهومه -

ا- القياس عموما اما ان يكون مباشرا كما يحدث عندما نقيس طول شخص ما اذ ان اطوال الاشياء واوزانها مثلا يمكن قياسها بنحو بسيط ودقيق باستخدام مقاييس دقيقة وبسيطة،وذلك لبساطة مثل هذه الخصائص ووضوحها ، او ان يكون غير مباشر كما يحدث عندما نقيس سمات شخصية الانسان واستعداداته العقلية والتحصيل وما شابه ذلك، اذ يتم هذا القياس باختبار يفترض انه يقيس سمة او قدرة معينة لدى الفرد وذلك من خلال مجموعة مواقف يستدل بها على مدى وجود السمو او القدرة المراد قياسها ، وهو اصعب من الاول كما انطبيعة الخصائص المعقدة تجعل الادواتالمستخدمة في قياسها معقدة ايضا ومن ثم تكون نتائجها اقل دقة من النوع الاول(عبد الرحمن واخرون ، ، ـ99 19 : 
العـــــــد السابع والثلاثون

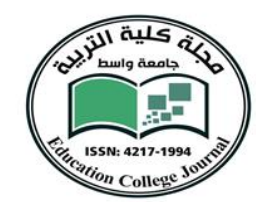

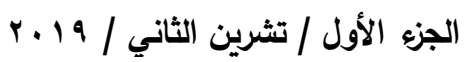

جامعة واسط

ץ-تستهدف عملية القياس الحصول على معلومات حول ظاهرة او سمة معينة وهذه المعلومات متصلة بوصف تلك الظاهرة او السمة ، وفي معظم الأحيان فان تفسير تلك القياسات يؤدي الى نوع

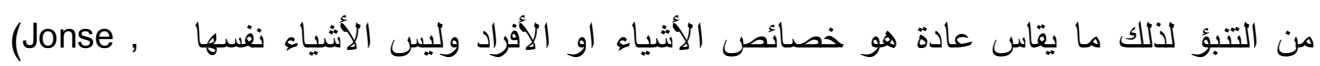
$.1971: 335$ )

r- يعرف براون ( Brown) مفهوم القياس النفسي بكونه " الاجراءات التي يتم بها التعبير عن

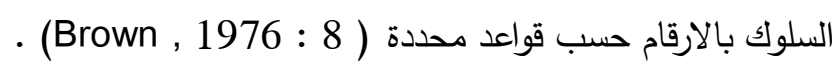

\section{تحليل الفقرات Item Analysis:}

يعد تحليل الفقرات احصائيا خطوة اساسية في بناء الاختبارات النفسية عموما والعقلية منها بشكل خاص ، واذاكان الهدف من بناء الاختبار هو ايجاد اختبار يتميز بالصدق والثبات في قياس السمة ،فان ذلك لا يتاتى الا من خلال ايجاد فقرات تتميز بالخصائص نفسها ، ومن ثم فان الاختبارت يمكن تحسينها من خلال انتقاء الفقرات الجيدة او استبدال الفقرات الضعيفة او تتقيحها ، لذلك رغم ان زيادة طول الاختبار يفترض نظريا ان يزيد صدقه وثباته ، فان تحليل الفقرات إحصائيا يقلل طول الاختبار وفي الوقت نفسه يزيد من صدقه وثباته

.(Anastasi, 1988: 202) (Magnusson, 1967: 197)

ان القضية النظرية الأساسية لإجراءات تحليل الفقرات هي إيجاد العلاقة الوظيفية بين معالم الاختبار ككل ومعالم الفقرات المختارة بشكل مناسب ـ مع ضرورة التحقق من مختلف العوامل التي تؤثر في معالم الفقرات مثل الخطأ العشوائي والتغيرات المنتظمة الناتجة من التغيرات في عوامل اخرى مثل طول الاختبار وتجانس عينة تحليل الفقرات وحجمها ( 14 : 1967, Gulliksen).

وفيما ياتي الهم الخصائص السيكومترية التي تعتمد عليها النظرية التقليدية في تحليل الفقرات :

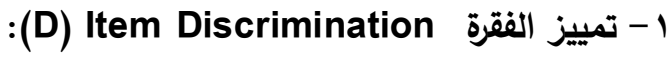

ان دليل تمييز الفقرة هو احد قياسات فعالية الفقرة في قياس السمة ، من خلال قدرتها على الكشف عن الفروق او التباين الذي يوجد فعلا بين الافراد ونظرا لصعوبة ايجاد فقرات تميز بين جميع المستجيبين ، ترى النظرية التقليدية ان الفقرة الجيدة هي التي تميز او تحدد الفرق بين المستجيبين 
العـــــــد السابع والثلاثون

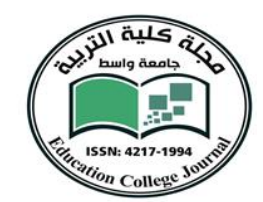

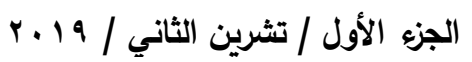

جامعة واسط مجلـــة كليـــــة التربيــــة

ذوي القدرة العالية وذوي القدرة الواطئة لذلك يتم اللجوء الى المجموعتين المتطرفتين في الارجة الكلية ( ) اذ تمثل الدرجة الكلية مجموع الفقرات في الاختبار بافتراض ان الاختبار (Extreme - groups) هو عينة للنطاق السلوك ومن ثم تتم المقارنة بين عدد المفحوصين الذين اجابوا عن الفقرة بصورة صحيحة في المجموعتين العليا والدنيا ، وان الفقرة ذات التمييز المثالي الفعال هي تلك التي يجيب عنها بصورة صحيحة كل الافراد في المجموعة العليا ، في حين يجيب عنها بصورة مخطئة كل .

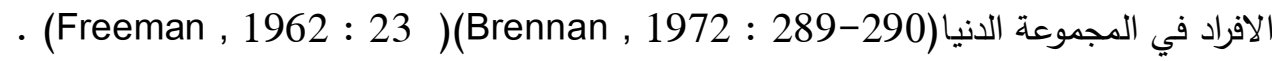

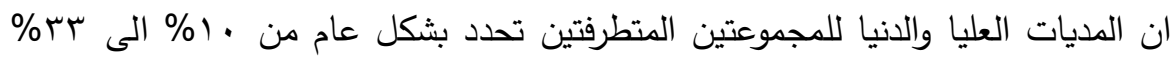
من العينة المرتبة على اساس الدرجة الكلية في الاختبار ، واذا كانت الدرجات تتوزع بشكل طبيعي

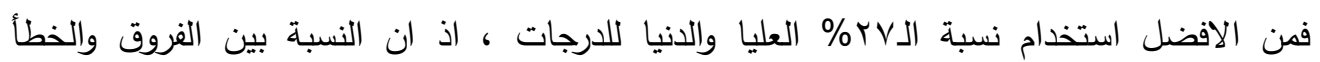
المعياري تبلغ اقصاها عند هذه النسبة . واذا كان التوزيع مسطح اكثر من الطبيعي فان النسبة

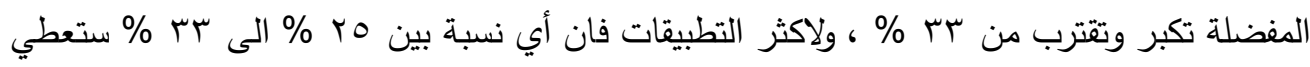
(Anastasi, 1988: 213) Agostino \& Cureton , 1975 : تقديرات متشابهة لمؤشر التمييز . ( D’49)

وتختلف صيغ حساب دلائل التمييز في نظرية الاختبار التقليدية تبعا لطبيعة القياسات والمتغيرات للسمة المقيسة وافتراض توزيعها ، أي هل كانت السمة المقيسة ثنائية او متصلة وهل

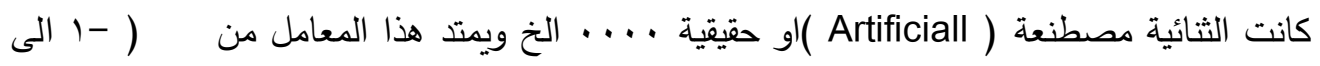
- (Anastasi, 1988: 212-217) (1+ لقد اشار اوسترهوف (Oosterhof, 1976) الى ان علماء القياس لم يتفقوا حول أي من الطرائق التي هي اكثر ملاعمة لحساب تمييز الفقرة ، واثبتت نتائج دراسته ان معظم هذه الدلائل تعطي نتائج متشابهة ، لذلك ينبغي ان يستتد تفضيل أي منها الى الملاءمة الاحصائية وسهولة حسابها وتفسيرها ( 149 - 145 : Oosterhof,1976)، الا ان معظم هذه الدلائل يعتمد على المجموعات المتطرفة او على معامل الارتباط ( Magnusson,1967:198).

ب (D) Item Reliability 
العـــــــد السابع والثلاثون

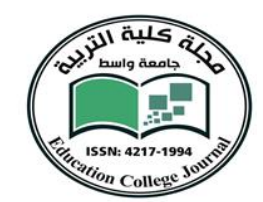

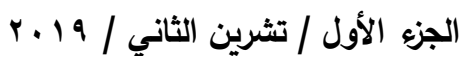

جامعة واسط مجلـــة كليـــــة التربيــــة

ان دليل ثبات الفقرة هو قياس اسهام الفقرة في تباين الاختبار الكلي ومن ثم في ثباته ، أي يفحص ثبات الفقرة لتعرُف على هل كان ثبات الاختبار سيزيد عند اضافة تلك الفقرة او لا ، وهذا يتم بفحص هل كانت الفقرة تقيس العامل نفسه الذي تقيسه الفقرات الاخرى او لا؟ ان الارتباط الموجب بين الفقرة المطلوب فحص ثباتها والفقرات الاخرى في الاختبار ستثير الى هل كانت تلك

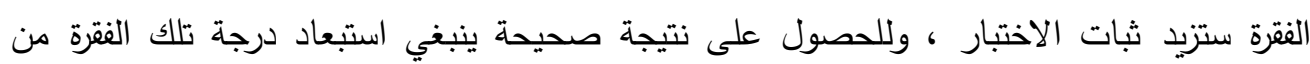
الدرجة الكلية عندما يحسب معامل الارتباط (215-1967:214).

ويمكن ان يحسب ثبات الفقرة بطريقة الاحتمال المنوالي (Modal Probability ) عندما

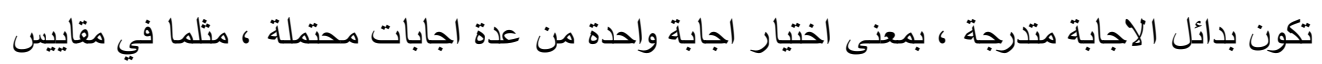

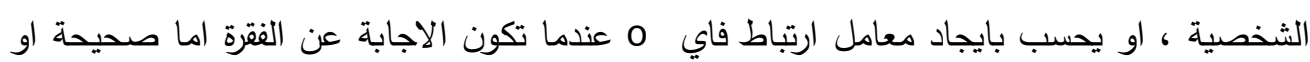

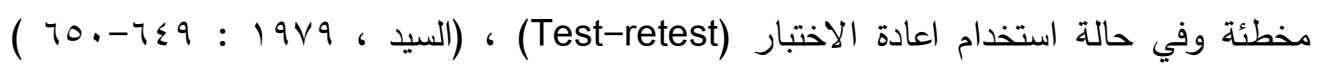

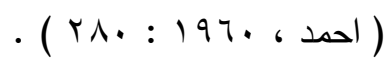

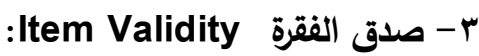

على الرغم من ان دليل التمييز يعد احد مؤشرات صدق الفقرة ، ان النظرية التقليدية تنظر لارتباط الفقرة بمحك خارجي او داخلي بوصفه الدليل الانسب لصدق الفقرة ، لان الفقرة الصادقة هي التي يجب ان تقيس الخصيصة المراد قياسها سواءاجاب عنها المفحوص بالرفض او الموافقة او سواء

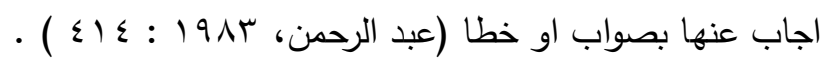

ونظرا لعدم توافر الدليل الخارجي في اكثر الاحوال بالرغم انه المفضل ، فعادة ما يستخدم

ارتباط الفترة بمحك داخلي هو الدرجة الكلية في الاختبار ، وهنالك في الاقل خمسة معاملات ارتباط تستخدم بشكل شائع لتشير الى ارتباط الفقرة بالمحك ، هي ارتباط بايسيريال وبوينت بايسيريال وتتراشورك ومعامل فاي وبيرسون ، وتتوقف ملاعمة أي منهم لقياس الارتباط على طبيعة مستويات قياس المتغير ونوع الفقرة ، ويعني الارتباط ان الفقرة تقيس المفهوم او القدرة نفسها التي تقيسها الدرجة الكلية ،وفي ضوء ذلك يتم الابقاء على الفترات التي تكون معاملات ارتباط درجاتها بالدرجة الكلية

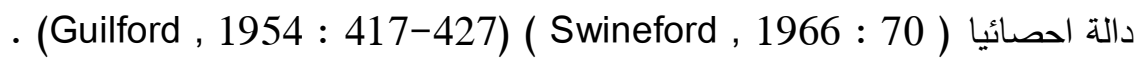


العـــــــد السابع والثلاثون

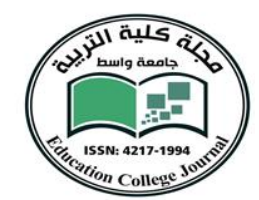

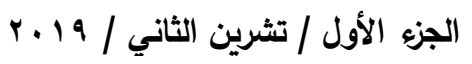

جامعة واسط

مجلــــة كليــــة التربيــــة

ان ارتباط الفقرة بالدرجة الكلية يحسب غالبا في الاختبارات الوجدانية بمعامل ارتباط بيرسون لان الاجابة عن

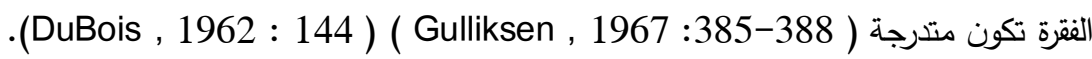

\section{ه - فعالية البدائل الخاطئة Efficency of Distracters:}

على الرغم من ان فعالية البدائل المخطئة هي ليست خاصية سيكومترية ، انها اجراء اساسي في تحليل الفقرات عند استخدام اختبار من نوع الاختيار من متعدد ، والهدف من هذا الاجراء هو ايجاد بدائل اجابة فعالة أي جذابة للمفحوصين على الرغم من انها بدائل مخطئة ، وهنالك عدد من المحكات التي ينبغي وضعها بالحسبان عند الابقاء على البدائل الخاطئة اهمها ما يأتي:

ا- - ان البديل المخطئ يجب ان يختاره المفحوصون الاقل قدرة اكثر ممايختاره المفحوصون

$$
\text { الاعلى قدرة - البديل }
$$

ץ- ان متوسط درجات المفحوصين الذين اختاروا كل بديل مخطئ يجب ان يكون اقل من متوسط

$$
\text { درجات الذين اختاروا البديل الصحيح( 143-138 : Henrysson , } 1971 \text { : }
$$

الخصائص السيكومترية للاختبار :

لا يعد الاختبار اداة صالحة للقياس الا اذا توافرت فيه شروط معينة وتعد هذه الشروط

بمثابة اهداف يحاول مصمم الاختبار تحقيقها في اثناء تصميمه الاختبار ، وانه ايضا مطلوب منه ان يقدم البراهين والادلة على توافر هذه الشروط للاختبار وهذه الشروط نفسها تستخدم عند اختيار الاختبارات للاستخدامات المختلفة عند المقارنة بين عدة اختبارات لاختيار اصلحها لغرض معين واهم هذه الشروط صدق الاختبار ويليه ثبات الاختبار

\section{:Validity الصدق}

ان الصدق هو احد المفاهيم الاساسية في مجال القياس النفسي بنحو عام وفي نظرية الاختبار التقليدية بنحو خاص • وبحسب هذه النظرية فهو يعني ان الاختبار يقيس بشكل دقيق ما صمح لقياسه ، أي يكون الاختبار صادقا الى المدى الذي يقيس البناء المعين ولا يقيس متغيرات دخيلة

لذلكيركز مفهوم الصدق في الاجابة بشكل تحليلي عن اسئلة مثل : هليقيس الاختبار السمة التي صمم لقياسها ؟ وما النسبة المئوية للتباين في درجة الاختبار المعزوة للمتغير الذي يقيسه الاختبار ؟ 
العـــــــد السابع والثلاثون

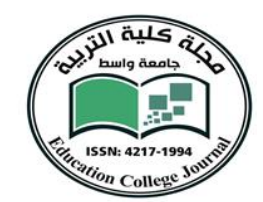

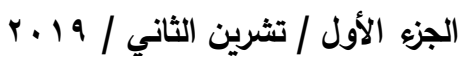

جامعة واسط

وبماذا يمكن ان نتتبأ من درجات الاختبار ؟ وهل يقدم الاختبار معلومات يمكن استخدامها في اتخاذ قرارات ؟ وما افضل طريقة لقياس ما يقيسه الاختبار ؟ ( 62 : Brown , 1976.

والصدق في حقيقة الامر هو صدق لنتائج المقياس او درجات الاختبار ، لا كما يذكر

لتسهيل الاستخدام بصدق المقياس ، وهذا ما يتفق مع تعريف ايبل (Ebel )للصدق بانه " دقة

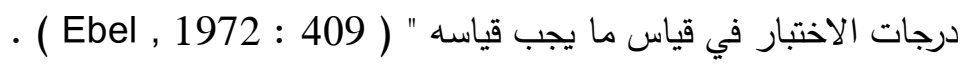

ولان تحديد معنى الصدق يمكن ان يتضمن مختلف القضايا والإجراءات ، فالصدق

كالاتساق يكون دائما محددا بموقف معين " موقفي " اذ انه تحت ظروف مختلفة وباستخدام عينات وطرق تحليل مختلفة سوف يعطي نتائج مختلفة ، وهكذا يستطيع المرو ان يتحدث بشكل صحيح فقط

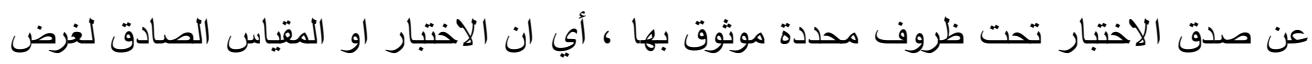
معين قد لا يكون صادقا لغرض اخر ، وقد يكون صادقا لمجموعة من الافراد ولا يكون صادقا لمجموعة اخرى للغرض نفسه ، كما قد يكون صادق في ظروف معينة ولا يكون صادقا في ظروف

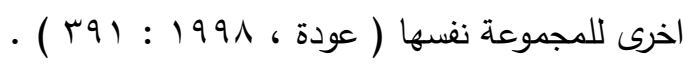

\section{وصدق الاختبار يحدد دائما اما بوساطة:}

ا- المدى الذي يقيس فيه الاختبار السمة المفترضة او البناء او المحتوى المراد قياسه .

(Extra r- او العلاقة بين درجات الاختبار وقياس لمحك اختبار خارجي

. Test Criterion)

ويعرف الصدق احصائيا بانه نسبة للتباين الحقيقي المرتبط بأغراض المقياس او

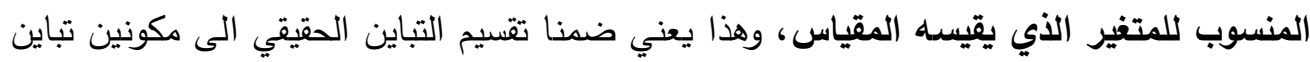

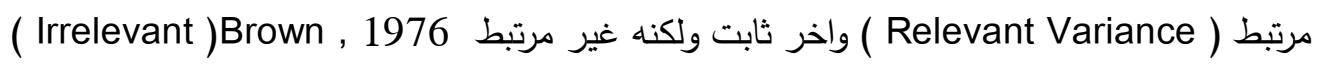


العـــــــد السابع وإلثلاثون

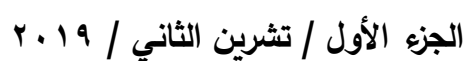

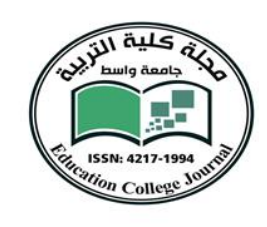

جامعة واسط

مجلـــة كليـــة التربيــة

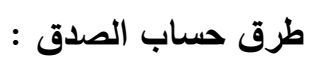

بالرغم من ان مفهوم الصدق واحد ، ان هنالك عددا من التصنيفات الممكنة لانماط الصدق

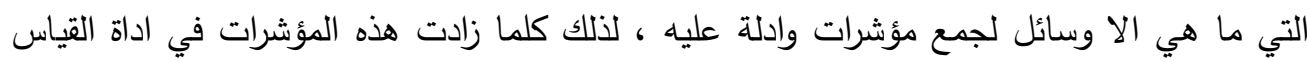

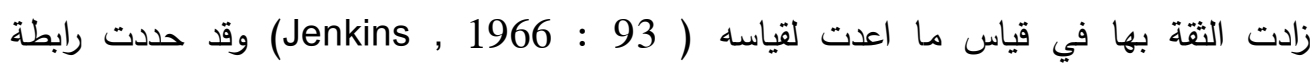
السيكولوجين الامر يكان ثلاثة انماط اساسية للصدق هي : الصدق المرتبط بمحك وصدق المحتوى وصدق البناء ويمكن وصفها على النحو الاتي .

أ- صدق المحتوى Content Validity:

في هذا الموقف فان باني المقياس يريد ان يجيب عن السؤال : الى أي حد يكون المقياس

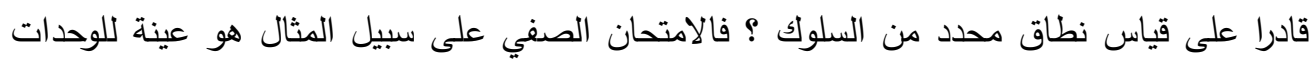
الهعطاة في فصل ( Course ) دراسي ، ومن ثم فان الدرجات في عينة هذه الفقرات ( الامتحان

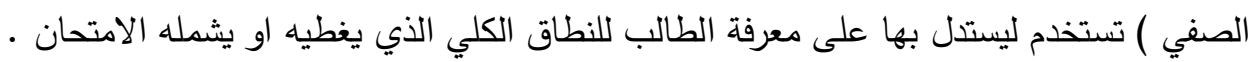

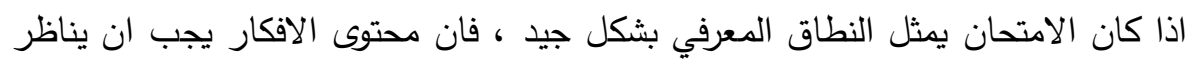

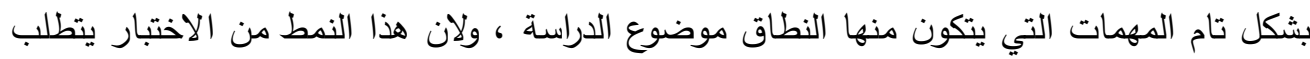

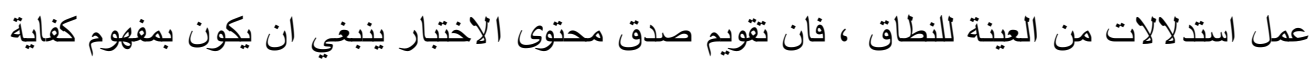

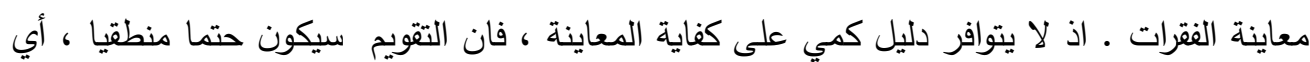
عملية اصدار حكم من خبراء مختصين بالموضوع حول مدى تمثيل الاختبار للمحتوى المراد قياسه ) ( .Pidgeon \& Yates, $1974: 67$ )

ويعد هذا المؤشر افضل مؤشرات الصدق في الاختبارات التحصيلية التي غالبا ما تستخدم

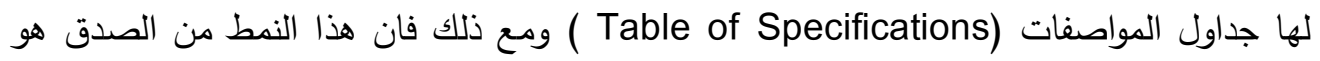
اكثر مؤشرات الصدق عرضة لاخطاء التقدير لان تقديرات المحكمين قد تتأثر بأحكامهم الذاتية .(Helmstadter , 1966 : 90 ) ب- صدق البناء Construct Validity: ان السؤال المباشر في هذا الموقف هو ما السمة التي يقيسها المقياس ويطلق على هذا النمط احيانا صدق المفهوم او صدق التكوين الفرضي لانه يعتمد على التحقيق التجريبي من مدى هي لئي 
العـــــد السابع والثلاثون

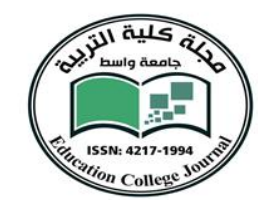

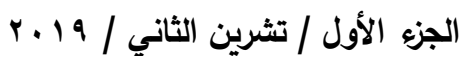

جامعة واسط

تطابق درجات مقياس مع المفاهيم والافتراضات التي اعتمد عليها الباحث في بناء الاختبار ( اسعد ،

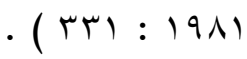

لذلك يتطلب صدق البناء تحديد بعض الافتراضات او المفاهيم النظرية والتحقق منها

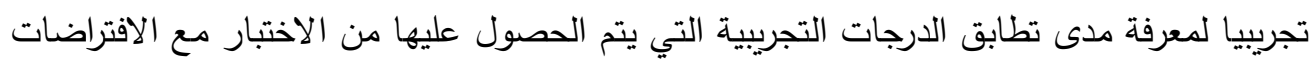

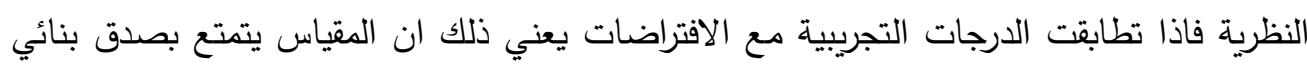

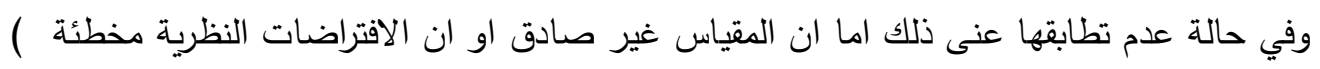
.Bechtoldt , 1959 : 621)

وقد تتباين الافتراضات او المفاهيم النظرية التي يستند اليها الباحث في بناء الاختبار او المقياس

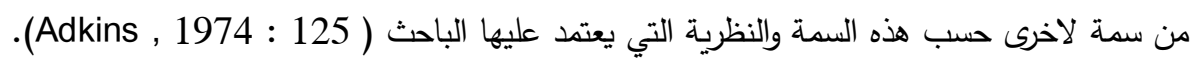

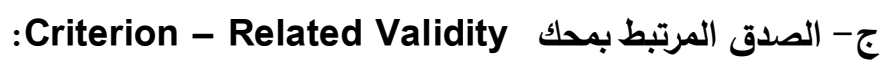
ان الصدق المرتبط بحكك يلائم ويرتبط بالتقنية التجريبية لدراسة العلاقة بين درجات )

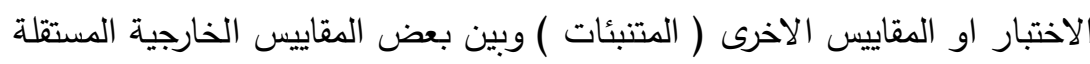

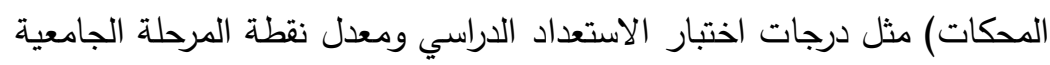

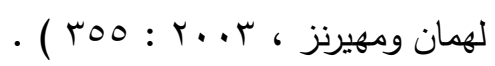
ويتطلب هذا النمط من الصدق توافر محك يتسم بصفات الهمها :

1. ان يكون المحك ذا صلة بالسلوك الذي يقيسه المقياس .

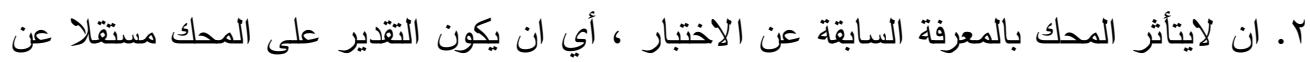

$$
\begin{aligned}
& \text { التقدير على المقياس . }
\end{aligned}
$$

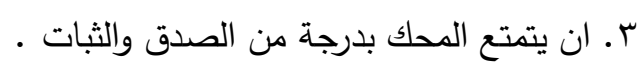

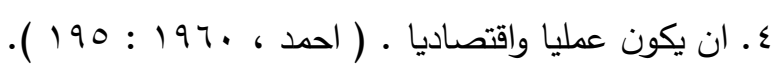

$$
\begin{aligned}
& \text { انواع الصدق المرتبط بمحك: }
\end{aligned}
$$

تميز ادبيات القياس والتقويمبين نوعين من الصدق المرتبط بمحك احدهما يسمى الصدق

،Concurrent Validity التبؤي Predictive Validity، والاخر يسمى الصدق التلازمي وفيما يأتي توضيح لكل نوع : 
العـــــــد السابع وإلثلاثون

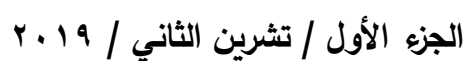

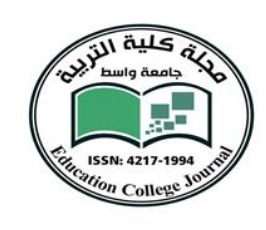

1- الصدق التنبؤي Predictive Validity:

تتعلق ادلة الصدق التنبؤي (Predictive Validity) بتقدير مدى صلاحية المقياس فيالتتبؤ باداء الفرد المستقبلي الذي يقاس بمقياس محك باستخدام درجات مقياس يطبق عليه في الوقت

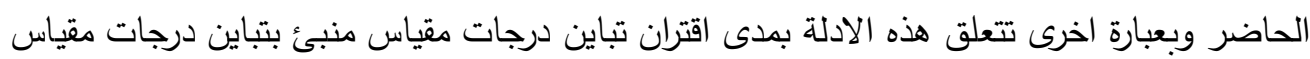

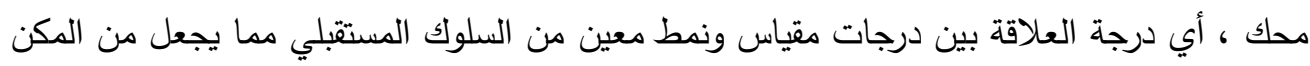

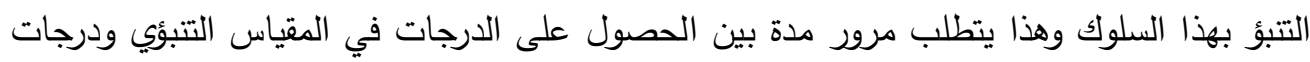

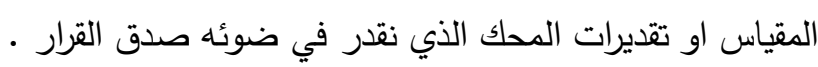

ب - بالصدق التلازمي Concurrent Validity

يتعلق بدرجة اقتران تباين درجات مقياس بتباين درجات مقياس اخر يطبق في الوقت نفسه

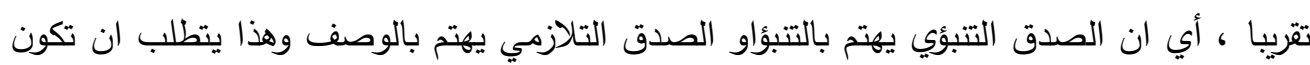

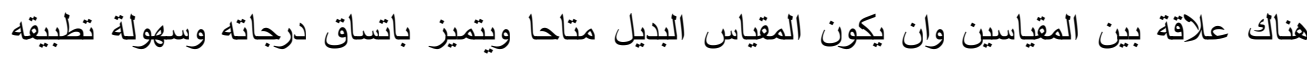

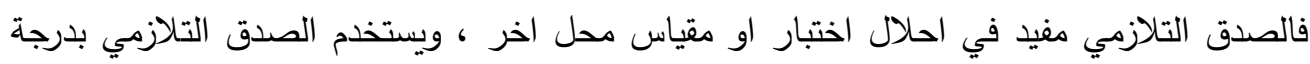

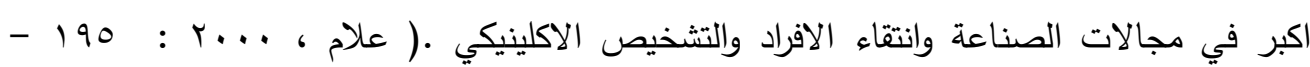
$\cdot(r \cdot 9$

\section{r Reliability الثبات}

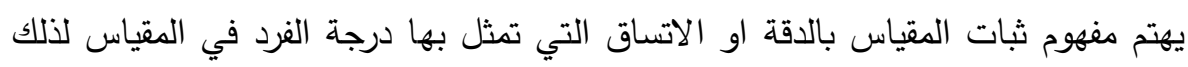

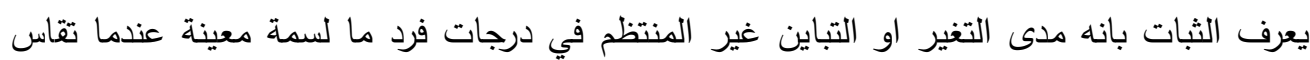

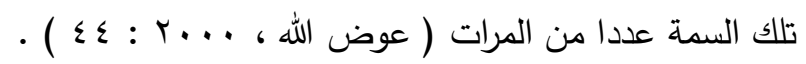

ولذلك طورت النظرية التقليدية مفهوم المقياس المتماثلة ( Paralle Tests) للتعامل نظريا مع الخطا العشوائي الذي يحدث في اعادة الاختبار عددا من المرات وعرفت الاختبارات المتماثلة

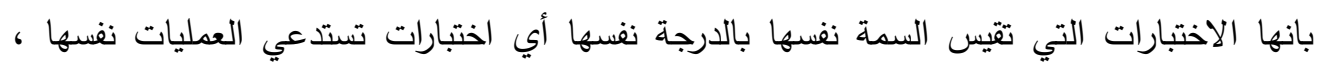

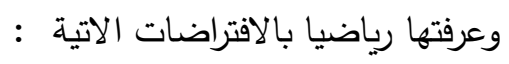


العـــــــد السابع والثلاثون

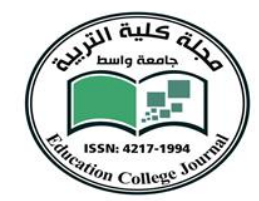

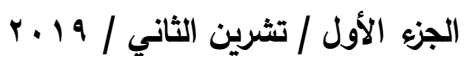

جامعة واسط

مجلـــة كليـــــة التربيــــة

ا ـ بما ان الدرجات الحقيقية ثابتة بالنسبة للافراد ومن ثم ستكون متساوية في عدد من الاختبارات

المتماثلة وبالتبعية فان المتوسطات والانحرافات المعيارية للدرجات الحقيقية لمجموعة من الافراد

في عدد من الاختبارات المتماثلة تكون متساوية .

r ـ الدرجات في كل الاختبارات المتماثلة مرتبطة بعضها ببعض بالدرجة نفسها وكذلك مرتبطة مع

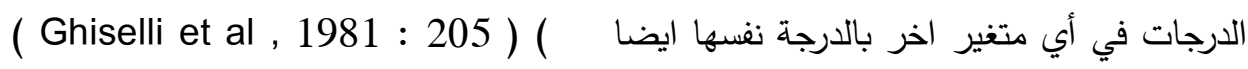

. Gulliksen ,1967 : 14 )

ويمكن التحقق من ثبات الاختبار بطرائق عدة تختص كل منها بتقدير نوعية معينة من

تباين الخطا ، ومن هذه الطرائق :

أ- طريقة اعادة الاختبار ( Test - Retest ) وتتبت هذه الطريقة بتقدير استقرار (Stability)

الاداء عبر الزمن من خلال تطبيق الاختبار واعادة تطبيقه على العينة نفسها بفاصل زمني

وحساب معامل الارتباط بين درجات التطبيقين ليمثل معامل الثبات ويسمى معامل الاستقرار

.(Guttman , 1956 : 81 )

ب- طريقة الصور المتكافئة ( Equivalent Forms): وتهتم هذه الطريقة بحساب التتاظر بين درجات صورتي الاختبار من خلال حساب معامل الارتباط بين درجات الافراد انفسهم في

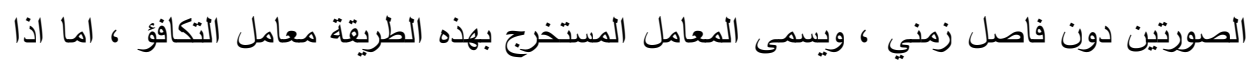
تم تطبيق الصورتين بفاصل زمني فان معامل الارتباط بينهما يمثل معامل الاستقرار والتكافؤ في

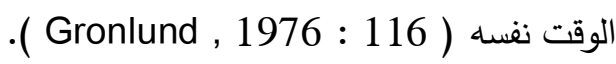

ج- طريقة التجزئة النصفية ( Split - Half ) وتهتم هذه الطريقة بحساب الاتساق الداخلي بين جزأي الاختبار ، اذ يقسم الاختبار على قسمين بطريقة مناسبة ليمثلا صورتين متكافئتين ويحسب الارتباط بينهما وهنالك عدد من المعادلات الخاصة بتعويض معامل الثبات المحسوب من النصفين ليصبح مناسبا للاختبار الكلي (Holzinger,1962:300 ). د - طريقة تحليل التباين Analysis - Variance): وتهتم هذه الطريقة بحساب الاتساق الداخلي بين فقرات الاختبار ، وهنالك ايضا معادلات عدة لحساب الثبات لهذا الغرض منها معادلتا كيودر - ريتشاردسون · r و اب ( KR21 20 KR21 ) ومعادلة ( الفا - كرونباخ )

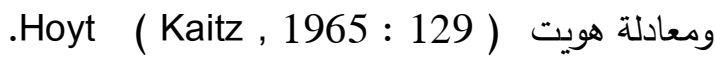


العـــــــد السابع والثلاثون

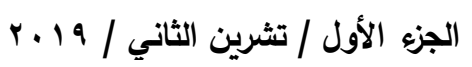

جامعة واسط مجلـــة كليــــة التربيــــة وامسة

r- الخطا المعياري للقياس: The Standard Error of Measurement

بحسب النظرية التقليدية فان خطأ القياس هو المشوه الاساسي للدرجة الحقيقية ، لذلك تحاول هذه

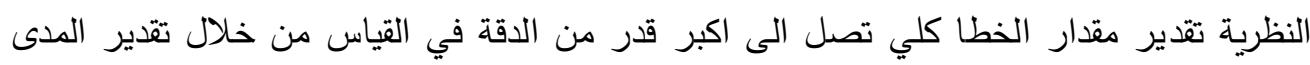
الذي تقع ضمنه الدرجة الحقيقية .

ونظرا لعدم معقولية اعادة الاختبار الى ما لانهاية من المرات على الشخص نفسه للحصول

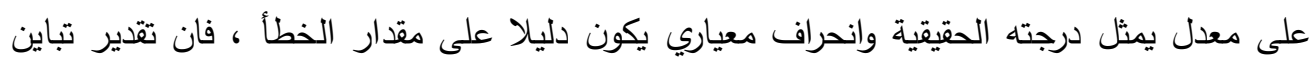

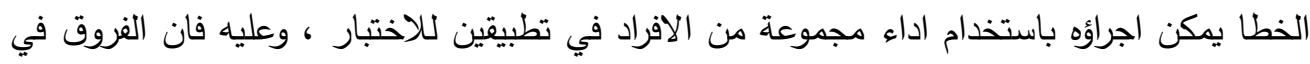
درجات الافراد في التطبيقين هي اخطاء القياس ، وبالاستفادة من معامل الثبات وعلاقة تباين الخطأ

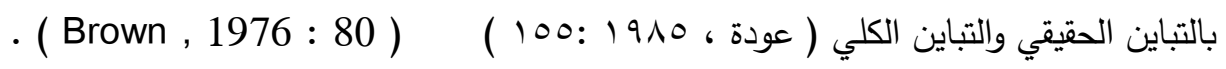

كما ان نظرية المقياس التقليدية تضيف في حساب الذطا المعياري للقياس افتراضين

$$
\text { اخرين هما : (ان دات }
$$

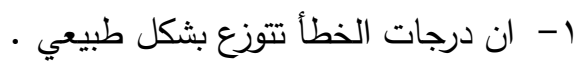

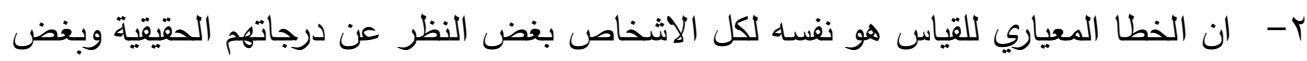

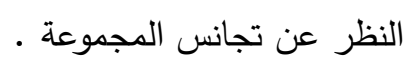

ويستخدم الخطأ المعياري للقياس في حساب فترات الثقة ( Confidence Intervals )

التي يمكن ان تقع ضمنها الدرجة الحقيقية .

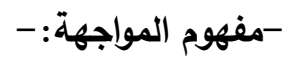

في القرن التاسع عشر ظهر الاهتمام بعمليات المواجهة أو التعامل مع الضغوط و كان

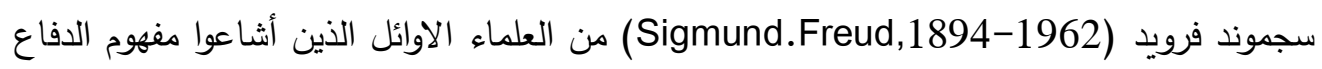

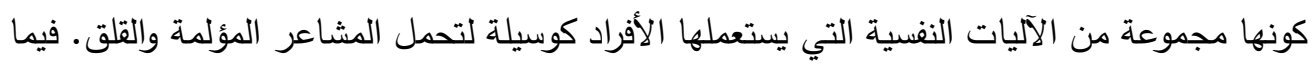

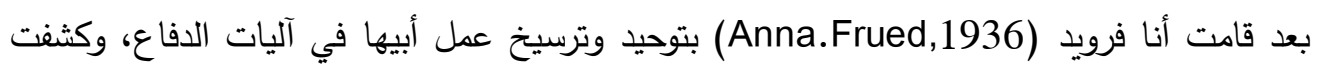
عن العديد من الآليات الإضافية.

ومنذ أواخر السبعينيات بدأت الدراسات الكلاسيكية من قبل موس (Moos,1976)

وبيرلنوسكولر (Pearlin\&Schooler,1978) وفولكمانولازاروس (Folkman\& Lazarus,1980) 
العـــــــد السابع والثلاثون

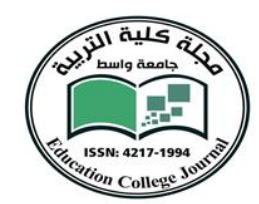

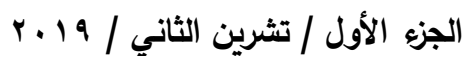

جامعة واسط

مجلـــة كليـــــة التربيــــة

وهوبفولوشوارزر وكوهن (Hobfoll Schwarzer\&Chon,1998) وبدأ مفهوم المواجهة يأخذ المدى الاوسع من بين مواضيع البحوث والدراسات في كل علم النفس(Schmaling\&Sher,2000:620).

وتعد المواجهة هي احد مكونات تفاعل الفرد مع البيئتين الخارجية والداخلية، وهي تعني

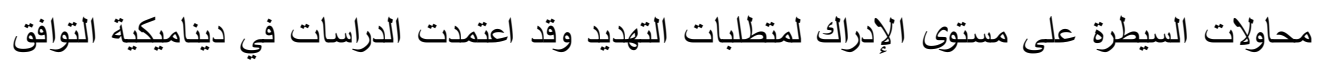

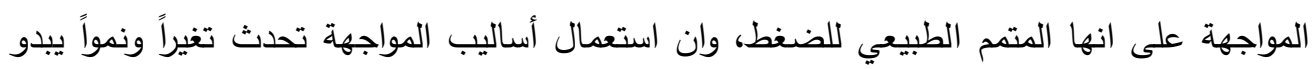
كربط بين تأثير الضغط والتوافق (الحلو، 1990 19، 9 (1).

والمواجهة تشمل كل الأشياء التي يفعلها الأفراد للتحكم، و التحمل، أو تقبل تأثيرات ضغوط الحياة،

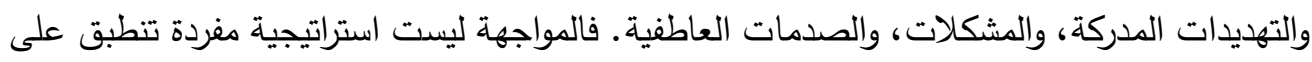

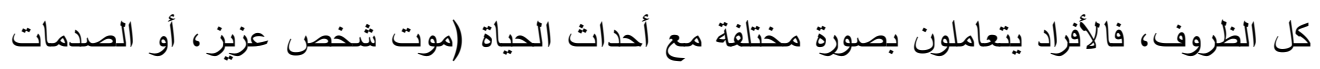

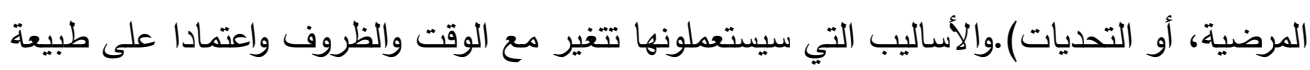

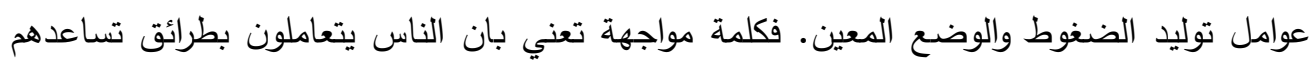

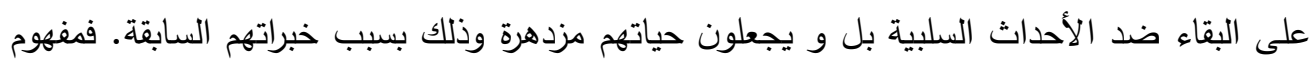

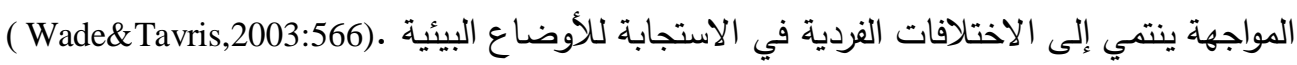
الدراسات السابقة :

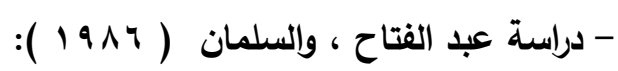

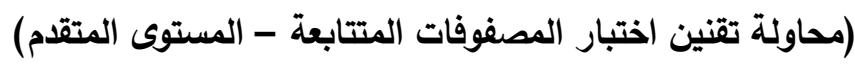

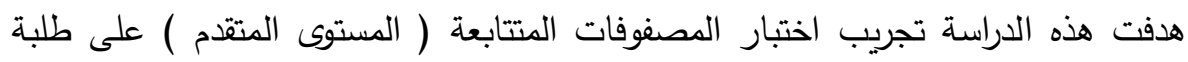

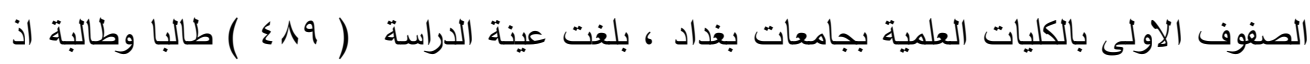
تمثل هذه العينة ما يساوي ( 1 \% \% ) من افراد المجتمع الاصلي تقريبا ، وتم استخدام اختبار

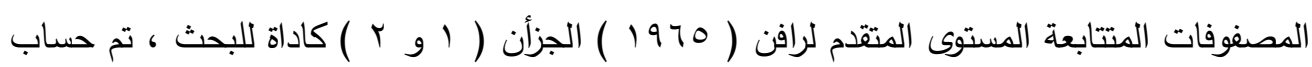

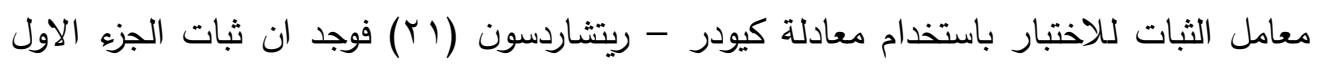

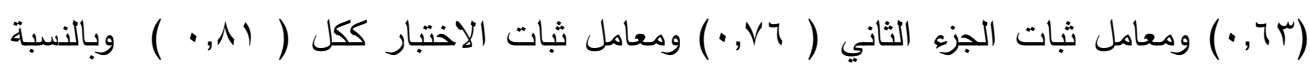

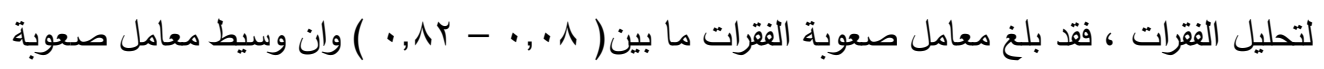

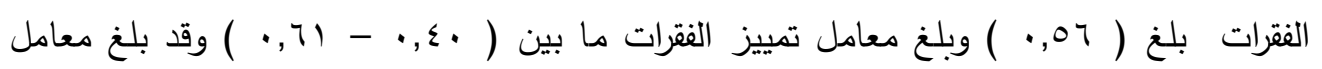


العـــــــد السابع والثلاثون

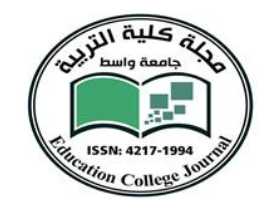

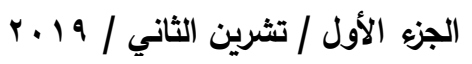

جامعة واسط

الارتباط بين جزأي الاختبار باستخدام معادلة ارتباط بيرسون ( عاب, ) ولاستخراج المعايير تم

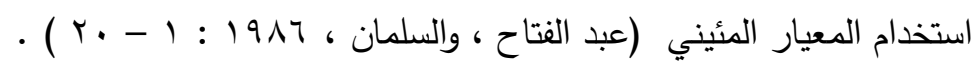

- دراسة بحر العلوم ( $19 \wedge V$ ) (

(بناء معايير وطنية لاختبارات فلانجان لتصنيف الاستعدادات بالمهن الهندسية)

استهدفت الدراسة اعداد معايير وطنية لاختبارات فلانجان لتصنيف الاستعدادات ولتحقيق

ذلك اختار الباحث ( V ) اختبارات من اصل ( 19 ) اختبارا في البطارية ، وهي الاستدلال ، المقاييس و المكونات و الميكانيك و التجميع والحكموالفهم ، وقد ترجمت هذه الاختبارات الى اللغة العربية واجريت بعض التعديلات عليها بعد ان تم عرضها على عدد من المختصين لتعرًف صدق الترجمة ، ثم طبقت هذه الاختبارات على عينتين استطلاعيتين اختيرتا عشوائيا للتاكد من وضوح اللغة وسلامتها وضبط الوقت الذي يستغرقه اجراء تلك الاختبارات ، ثم طبق اختبار الاستدلال والحكم على عينة عشوائية لحساب الخصائص السيكومترية لهما ، كما طبقت الاختبارات جميعها على عينة اشتقاق المعايير بحسب متغيرات الجنس والمنطقة الجغرافية ، اذ تم استخراج الدرجة المعيارية والمئينات والتساعيات لكل اختبار وفي ضوء ذلك اقترح الباحث ضرورة الاعتماد على هذه الاختبارات مع معايير اخرى للقبول في كليات الهندسة على اساس انها يمكن ان تكثف عن توافر الاستعدادت

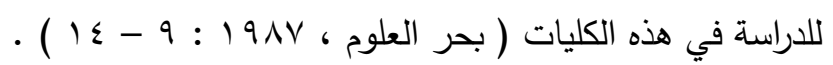

$$
\text { - دراسة الصغير ( ب ( ب ) ) }
$$

(تكييف بطارية الاستعدادات الفارقية على طلبة مراكز التدريب المهني في الاردن واستخدامها في تحديد الاستعدادات المسهمة بالنجاح في تخصصاتهم المهنية)

استهدفت هذه الدراسة تحقيق هدفان رئيسين هما تكييف بطارية الاستعدادات الفارقية على

طلبة مراكز التدريب المهني في الاردن ، والملتحقين ضمن برنامج التلمذة المهنية ، وتحديد الاستعدادات المسهمة بالنجاح في التخصصات المهنية لطلبة مراكز التدربب المهني التي يتضمنها برنامج التلمذة المهنية ، ولتحقيق ذلك قامت الباحثة بالاجراءات الاتية : 
العـــــــد السابع وإلثلاثون

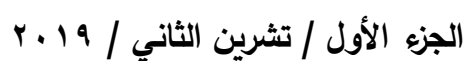

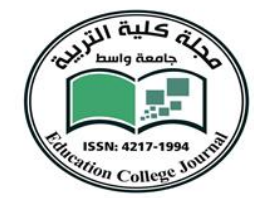

جامعة واسط

مجلـــة كليـــــة التربيــــة

* ترجمة اختبارات البطارية وتعليماتها وعرضها على مختصين وخبراء للتاكد من دقة الترجمة

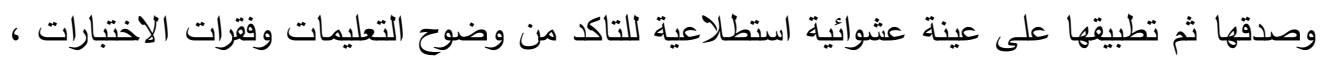
وفي ضوء ذلك عدلت ( مب ) فقرة من فقرات البطارية البالغ عددها ( . . م ) فقرة . * طبقت اختبارات البطارية على عينة التحليل الاحصائي البالغ عدد افرادها (

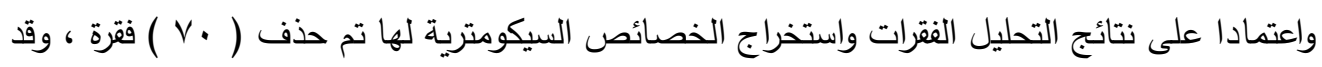
تراوحت معاملات صعوبة لاختبارات البطارية بصيغتها النهائية بين ( • ץ, · ) و ( •^, • ) وتراوحت

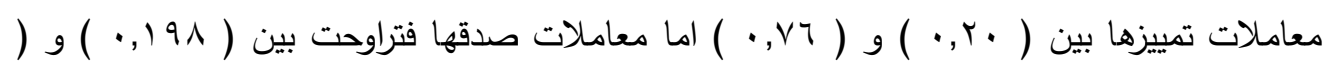
$\cdot(\cdot, T \wedge r$

* طبقت الاختبارات جميعها على عينة التطبيق الاساسية والبالغ عدد افرادها ( عبr ) طالبا وطالبة ، وتم استخراج الخصائص السيكومترية للاختبارات ( الصدق ، والثبات ) وكذلك حددت الاختبارات المسهمة بالنجاح في التخصصات المهنية المختلفة باستعمال الوسائل الاحصائية المناسبة ، وكذلك استخرجت معايير لها بشكل مئينات ، وكان ابرز النتائج الممتعقة بهدفي البحث ماياتي : 1- امكن تحديد الاختبارات المسهمة بالنجاح في التخصصات المهنية اذ اظهرت النتائج اسهامات

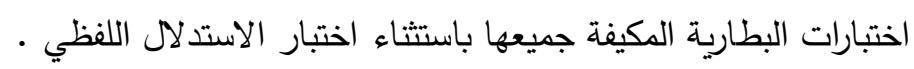
r- تتمتع اختبارات البطارية المكيفة بخصائص سيكومترية جيدة ممثلة بالصدق والثبات . r- اظهرت النتائج اسهامات الاختبارات لجميع التخصصات المهنية باستثناء التخصصات الاتية : باتهات التجميل والخياطة والمبيعات ، وقد يعود ذلك الى صغر حجم العينات في هذه التخصصات . واستتادا الى ما تم التوصل اليه من نتائج وضعت الباحثة مجموعة من التوصيات

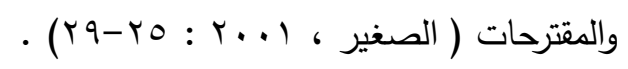

منهجيه وإجراء ات البحث: وتضمنت هذه الاجراءات تحديد منهجية الدراسة ومجتمع الدراسة ، واختيار عيناته ، وترجمة المقياس ووصفه، والتحقق من صدق الترجمة ، وحساب الخصائص السيكومترية لفقرات المقياس ، ، فضلا عن تحديد اهم الوسائل الاحصائية المستخدمة سواء اكان ذلك في الاجراءات ام في التحليل . methodlogy of the stuby : منهجية الاراسة عنة الاجة اعتمدت الباحثة منهج البحث الوصفي لتحقيق اهداف بحثها، ويعد هذا المنهج الأنسب استخداماً في

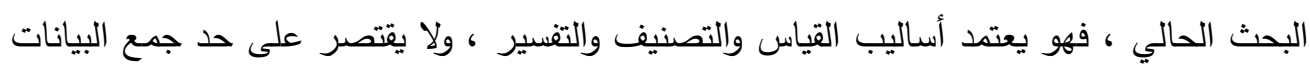


العـــــــد السابع والثلاثون

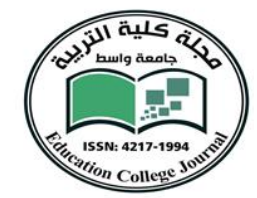

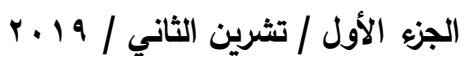

مجلـــة كليـــــة التربيـــــة

وتبويبها وإنما يتعدى ذلك إلى التحليل والتفسير والمقارنة والتقويم والوصول إلى تعميمات (عبد الرحمن

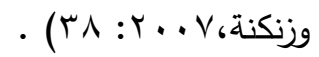

اجراءات البحث : search procedures

اولا : مجتمع البحث : search commuity

يتألف المجتمع من طلبة كلية التربية في جامعة واسط للدراسة الصباحية للعام

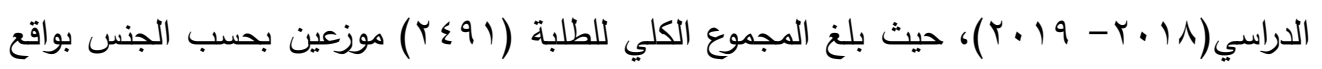

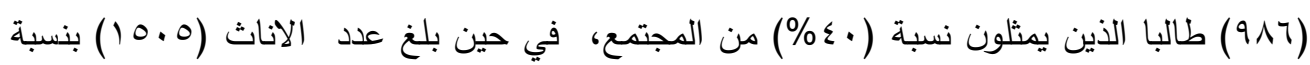

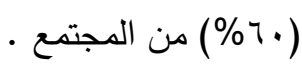

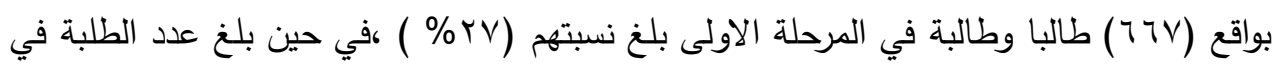
المرحلة الثانية(r9) طالبا وطالبة وتشكل نسبتهح (r^\%) ، في حين بلغ عدد الطلبة في المرحلة الثالثة (r^o) طالبا وطالبة وتشكل نسبتهم (rr\% ) ، في حين بلغ عدد الطلبة في

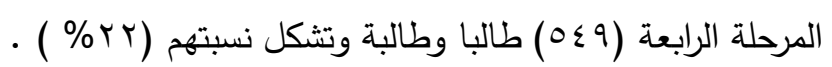

أداة البحث:search tool

اعتمدت الباحثة مقياس المواجهة الذي اعده العالم (cope Brief) الصادر عام 9 191 لطلبة المرحلة الجامعية • يتكون المقياس من (Y^) فقرة بتدرج (انا لا اقوم بهذا ابدا ، انا اقوم بهذا بنحو اقل ، اقوم

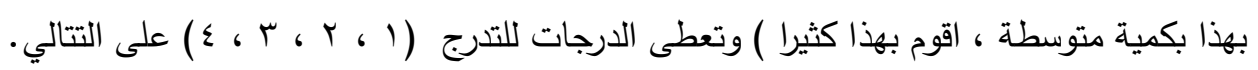
إجراءات تقنين المقياس: Standardization procedures مرت عملية تقنين المقياس بالخطوات الاتية :

1 - عرضت الباحثة المقياس على متخصص في اللغة الانكليزية لترجمته الى اللغة العربية(')،واعيد ترجمتها من اللغة العربية الى اللغة الانكليزية ( ' ') ، وروعي ان تكون الترجمة شاملة لجميع الافكار الرئيسة

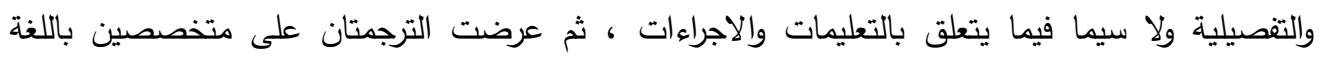
الانكليزية وذلك للتأكد من سلامة الترجمة ودقتها وصدقها واجريت بعض التعديلات في في ضواء التهات ملاحظاتهم.

rogical analysis of paragraphs : التحليل المنطقي للفقرات عرضدت فقرات مقياس المواجهة على ( ( ) محكمين من المتخصصين في العلوم التربوية والنفسية والقياس والتقويم للتأكد من توافر الخصائص المناسبة لهذه الفقرات وبدائلها من حيث الشكل 
العـــــــد السابع وإلثلاثون

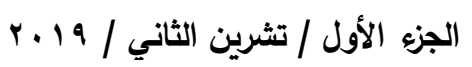

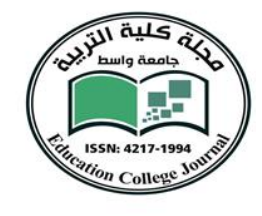

جامعة واسط

مجلـــة كليـــــة التربيــــة

والمضمون الظاهري ، ولتحليل آراء المحكمين في فقرات المقياس فقد تم استخدام اختبار (كاب ) لعينة واحدة ، وعدت كل فقرة صالحة عندما تكون مربع كأي المحسوبة دالة عند مستوى ( ه. . . ) وهي

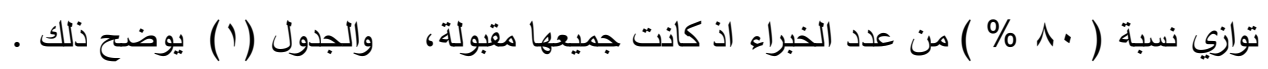

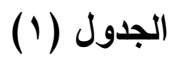

نتائج اختبار كاي لآراء المحكمين حول صلاحية فقرات المقياس

\begin{tabular}{|c|c|c|c|c|c|c|c|}
\hline مستوى الدلالة & كاب & قالمحسوبة كاب & النسبة & غير الموافقين & الموافقين & الفقرات & ت \\
\hline., .0 & $\Gamma, \wedge \varepsilon$ & 1. & $\% 1 \ldots$ & - & 1. & 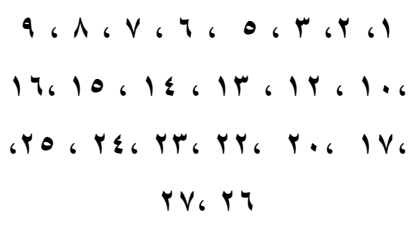 & 1 \\
\hline$\cdot, .0$ & $r, \wedge \leq$ & $7, \varepsilon$ & $\% 9$. & 1 & 9 & \& & r \\
\hline
\end{tabular}

وضوح التعليمات وفهم العبارات :

لغرض تعرُف مدى وضوح الفقرات وتعليمات المقياس ، فضلا عن تعرُف طريقة الإجابة على ورقة الاجابة المنفصلة ، و احتساب وقت اكمال الاجابة لغرض تحليلها إحصائيا، طبق المقياس ونعاس ونعات

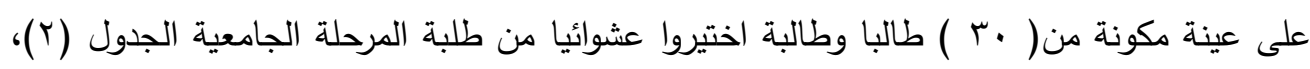

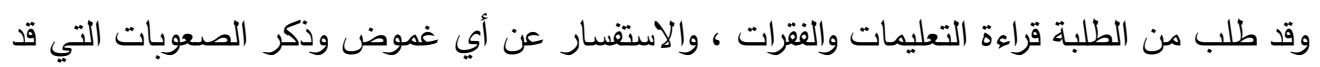
تواجههم في اثناء الاستجابة.

(r) الجدول

عينة وضوح التعليمات موزعة بحسب التخصص والجنس

\begin{tabular}{|c|c|c|c|}
\hline المجموع & 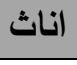 & ذكور & الاختصاص \\
\hline $1 \cdot$ & 0 & 0 & علوم تربوية ونفسية \\
\hline 1. & 0 & 0 & تاريخ \\
\hline $1 \cdot$ & 0 & 0 & جغرافية \\
\hline r. & 10 & 10 & المجموع \\
\hline
\end{tabular}


العـــــــد السابع والثلاثون

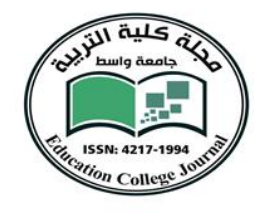

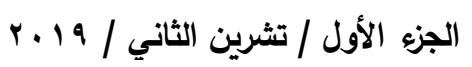

جامعة واسط

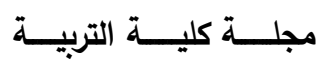

فتبين ان التعليمات واضحة ، وقد اوضحت التجربة ان مدى الوقت المستغرق للإجابة عن

المقياس بين ( • (19 1 ) دقيقة وبمتوسط يبلغ ( ع ا ) دقيقة.

altahlil alaihsayiyu lilfaqarat : التحليل الإحصائي للفقرات

تعد عملية التحليل الإحصائي لفقرات المقياس من الخطوات الأساسية لبنائه وان اعتماد الفقرات التي تتميز بخصائص سيكومترية جيدة يجعل المقياس اكثر صدقا وثباتا (192 : Anastasi , 1988 ( 192

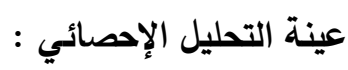
بغية تحديد حجم العينة المناسب في عملية التحليل الاحصائي لفقرات الاختبار و الاختبار ككل ، لا لإلهائ بد من الاشارة الى اراء بعض المختصين في القياس النفسي في هذا المجال يشير ليمك و وايرزما (

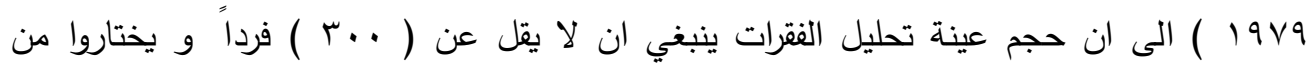

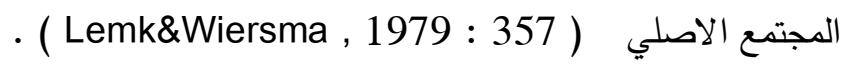
لذ بلغت عينة التحليل الاحصائي للفقرات ( . . إ) طالب وطالبة ، اختيرت هذه العينة بالطريقة الطبقية العشوائية من طلبة المرحلة الجامعية في كلية التربية في جامعة واسط، والجدول (r) يوضتح ذلك بالك

جدول (r)

حجم عينة التحليل الإحصائي موزعة بحسب المرحلة والجنس جلول

\begin{tabular}{|c|c|c|c|}
\hline العدد الكلي & اناث & 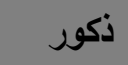 & المرحلة \\
\hline$\wedge$ & $\leqslant 9$ & re & المرحلة الاولى \\
\hline$\Lambda \varepsilon$ & 0 . & $r \varepsilon$ & المرحلة الثانية \\
\hline 79 & $\leqslant 1$ & rᄉ & المرحلة الثالثة \\
\hline 77 & $\varepsilon$. & ry & المرحلة الرابعة \\
\hline r.. & $1 \wedge$. & Ir. & المجموع \\
\hline
\end{tabular}

تصحيح المقياس :

بعد ان طبق على ( . . م ) طالب وطالبة من مجتمع البحث ، اعتمدت الباحثة في تصحيح المقياس بحسب البدائل في المقياس الاصلي ثم تحسب اجابات الطالب الموجودة في ورقة 
العـــــــد السابع والثلاثون

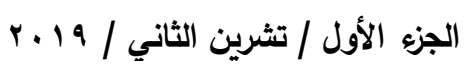

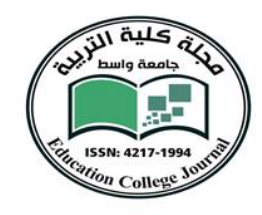

جامعة واسط

مجلـــة كليـــــة التربيــــة

الاجابة لتمثل الدرجة الخام للطالب ، وبعد تفريخ إجابات جميع افراد العينة في جدول خاص ، ولان

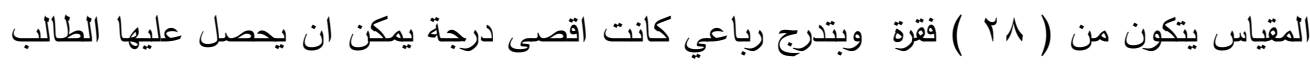

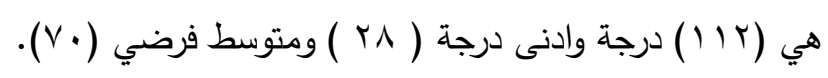

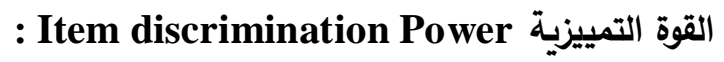

استخدمت الباحثة/سلوب المجموعتين المتطرفتين في استخراج القوة التمييزية من خلال الاتي:

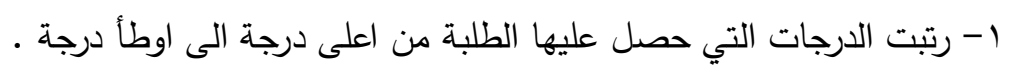

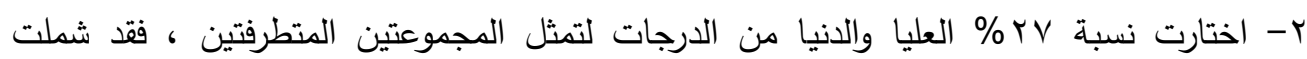

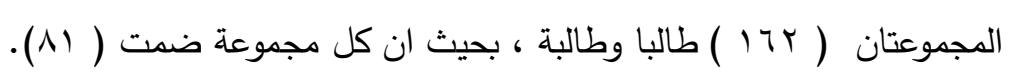

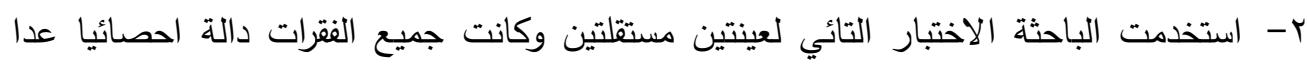

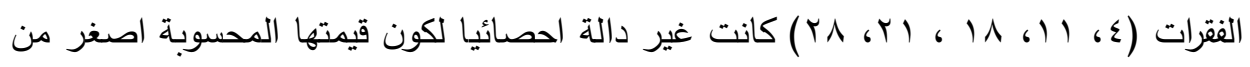

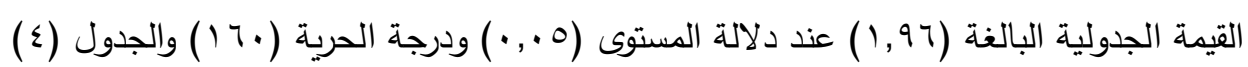
يبين ذلك.

\begin{tabular}{|c|c|c|c|c|c|c|}
\hline \multirow{2}{*}{ مستوى الدالة } & \multirow{2}{*}{ القيمة التائية } & \multicolumn{2}{|c|}{ المجموعة الدنيا } & \multicolumn{3}{|c|}{ المجموعة العليا } \\
\hline & & الانحراف & الوسط & الانحراف & الوسط & ت \\
\hline دالة & r, & $1, \cdot 1$. & $r, \vee \wedge$ & $\cdot, \wedge 01$ & r r & 1 \\
\hline دالة & $0,70 \wedge$ & 1,104 & $r, .0$ &., $9 \times q$ & $r, 1 r$ & $r$ \\
\hline دالة & $V, \cdot V \varepsilon$ & .,qr. & 1, 1, & $1, .7 r$ & $r, q r$ & r \\
\hline غير دالة & $\cdot, \diamond \wedge V$ & $\cdot, 91 \leq$ & o &., 970 & $1, r i r$ & $\varepsilon$ \\
\hline دالة & $0, q \wedge r$ & •, १ & $1,7 r$ & $1,0 \leq r$ & r,Vr & 0 \\
\hline
\end{tabular}

\section{الجدول (؛)}

القوة التمييزية لمقياس المواجهة ما وراء المعرفة 
العــــــدد السابع وإلثلاثون

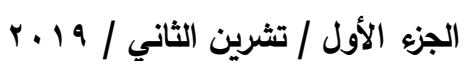

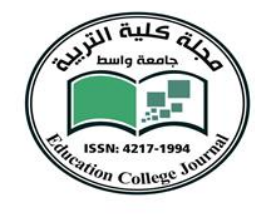

\begin{tabular}{|c|c|c|c|c|c|c|}
\hline دالة & 7,097 & $\cdot, \wedge \vee r$ & 1,71 & $1,1 \cdot 7$ & $r, \wedge \wedge$ & 7 \\
\hline دالة & $\{, \cdot V \downarrow$ & $1,1 \mathrm{rV}$ & $r, 1 \wedge$ & $1,11 r$ & $r, \cdot r$ & V \\
\hline دالة & r,YYq & $\cdot, \wedge \bullet \leqslant$ & $r, 0$. &.,$\leqslant 9$. & r,マ^ & 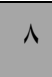 \\
\hline دالة & $r, \ldots$ & $1,1 \wedge 1$ & r,IV & $1,1 Y \leq$ & $r, \diamond \wedge$ & 9 \\
\hline دالة & $r, \wedge \leq r$ & 1,.rr & Y,q० & $\cdot, v \leqslant r$ & $r, \S \Gamma$ & 1. \\
\hline غير دالة & •, & 1,194 & Tr., & $1, .9 r$ & $1, r+4$ & 11 \\
\hline دالة & $0,1 \leq$. & $1,+\leqslant 1$ & $r, \cdot r$ & ש^ף, & ५,৭^ & Ir \\
\hline دالة & $\uparrow, . \wedge$. & $\cdot, 99 \leq$ & $1, \wedge r$ & $1,1.0$ & $r, \ldots$ & $1 \pi$ \\
\hline دالة & $0,1 \times 4$ & $1, \ldots \wedge$ & $r, \cdot r$ &., $9 \leq 4$ & Y,QD & $1 \varepsilon$ \\
\hline دالة & $0,9 \mathrm{rV}$ & $1, . r_{0}$ & 1,71 & $1, .1$ & $r, \vee \wedge$ & 10 \\
\hline دالة & $0,11 \mathrm{~V}$ & r, & $1, \Lambda$. & $1,1 \vee 7$ & $r, \Lambda$. & 17 \\
\hline دالة & $r, \wedge r$. & $1, \cdot \leq r$ & $r, Y, Y$ & $1, \ldots 7$ & r,q & IV \\
\hline غير دالة & , Arr & $1, .1$ & I,rrr & $1, \cdot r V$ & $1, \leqslant 04$ & 11 \\
\hline دالة & $\wedge, 799$ & $\cdot, V \leq \neg$ & 1,00 &., 999 & Y,q० & 19 \\
\hline دالة & $0, V \mu r$ & $\cdot, 9 \cdot \leq$ & 1, & $1,1 \wedge$ & $r, V Y$ & $r$. \\
\hline
\end{tabular}


العـــــــد السابع والثلاثون

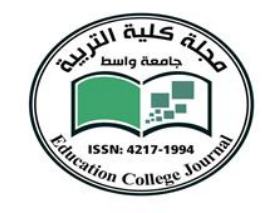

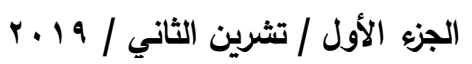

\section{جامعة واسط}

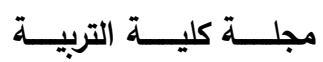

\begin{tabular}{|c|c|c|c|c|c|c|}
\hline غير دالة & $\cdot, \leqslant \leqslant V$ &., 799 & $1, r \circ 1$ & $\cdot, 9 \vee 7$ & $1, \leqslant 11$ & YI \\
\hline دالة & ץ, ૬५. & 1,101 & $1, \wedge \wedge$ & $1, r \vee r$ & r, ४ & rY \\
\hline دالة & $r, Y \leq r$ & $1, \cdot r V$ & $1, \vee \wedge$ & $1, r \leq \varepsilon$ & r,Yo & rr \\
\hline دالة & $r, . O V$ & $1, \cdot \mathrm{qq}$ & $r, \cdot v$ &., 9.9 & $r, \leqslant r$ & $r \varepsilon$ \\
\hline دالة & r,997 & $1, \cdot r r$ & $r, Y V$ & $1, . r r$ & $r, \cdot r$ & ro \\
\hline دالة & $\leq, V \leq 0$ & $1,1 \vee r$ & $r, 1 \wedge$ & $1, .17$ & $r, 1 r$ & rT \\
\hline دالة & r,^৭१ & 1,197 & $r, I V$ & $1,10$. & $r, \ldots$ & $r V$ \\
\hline غير دالة & $1, . \wedge 9$ & $1, .17$ & 1, & $\cdot, \wedge \cdot q$ & س & $r \wedge$ \\
\hline
\end{tabular}

الاتساق الداخلي Internal Consistency:

لتحقيق ذلك تم حساب قيم معاملات الارتباط بين درجة كل فقرة مع الدرجةالكلية لمقياس

المواجهةلدالطلبة، باستعمال معامل ارتباط بيرسون، حيث كانت الاستمارات الخاضعة للتحليل بهذا

الأسلوب ( . . r) استمارة وهي ذات الاستمارات التي خضعت للتحليل في ضوء أسلوب المجموعتين

المتطرفتين، وتبين أن جميع معاملات الارتباط كانت دالة إحصائيا عند مستوى (0. . • ) ودرجة حرية

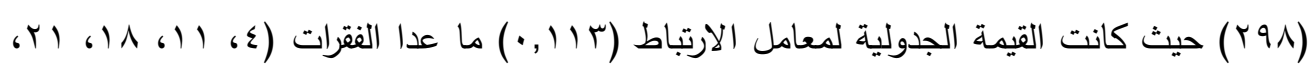

1 ץ)غير دالةوالجدول(0) يوضح ذلك. 
العـــــــد السابع وإلثلاثون

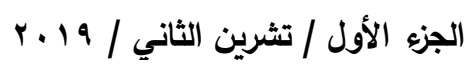

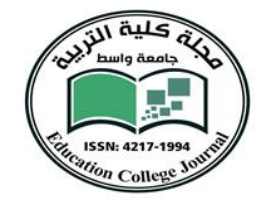

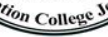

جامعة واسط

مجلـــة كليـــــة التربيــــة

جدول (0)

معامل الارتباط بين درجة كل فقرة والدرجة الكلية لمقياس المواجهة

\begin{tabular}{|c|c|c|c|c|c|c|c|}
\hline الفقامل ارتباط & ت & 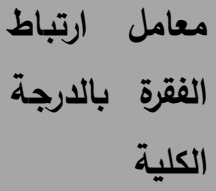 & ت & |الفقرة & ت & الفقلية بالدرجة & $ت$ \\
\hline • , & $r r$ & $\cdot, \leqslant V$. & 10 &,,$\varepsilon \ldots$ & $\Lambda$ & . & 1 \\
\hline.,$\varepsilon .0$ & $r r$ & • , $\leqslant V \Psi$ & 17 & •, $\{1 \leqslant$ & 9 & $\cdot, \varepsilon \cdot r$ & $r$ \\
\hline$\cdot, \varepsilon q r$ & $r \varepsilon$ & $\cdot, \leqslant 0 \leqslant$ & iv & . , , , & 1. & $\cdot, r \wedge q$ & $r$ \\
\hline$\cdot, r \leq \varepsilon$ & ro & $\cdot, \wedge r$ & 11 & $\therefore, \wedge 0$ & 11 &., $9 \leq$ & $\varepsilon$ \\
\hline$\cdot, r \vee r$ & $r q$ & $\cdot, \leqslant 11$ & 19 & • & ir & ., OrV & - \\
\hline$\cdot, r \circ q$ & $r v$ & $\cdot, \varepsilon \diamond \wedge$ & $r \cdot$ & $\cdot, \leq 79$ & ir & .,,$\sim q$ & 7 \\
\hline$\cdot, \cdot v_{1}$ & $r \wedge$ &., .9. & ri & $\cdot, \leqslant 91$ & $1 \leqslant$ & $\cdot, \leqslant 4 \wedge$ & $v$ \\
\hline
\end{tabular}

الخصائص السيكومتربة لمقياس المواجهة:

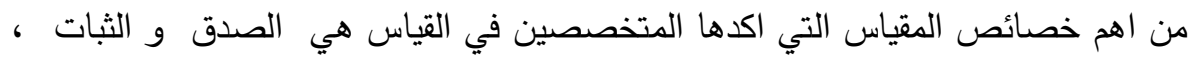
والحساسية والمعايير ، اذ تعتمد عليها مدنالدقة في بيانات او الدرجات التي تحصل عليها من

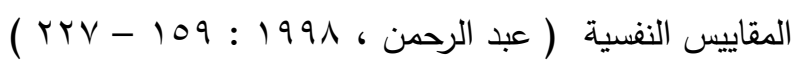


العـــــــد السابع والثلاثون

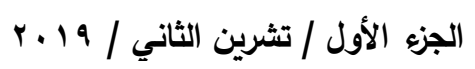

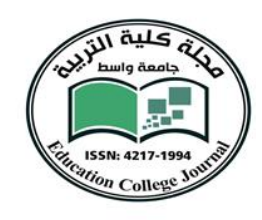

جامعة واسط

مجلــــة كليــــة التربيــــة

أولا. صدق الاختبار ValidityTest:

استخرج للمقياس الحالي مؤشران للصدق وهما (صدق ظاهري ، وصدق بناء ) وفيما يأتي

$$
\text { توضيح لكيفية الحصول على كل مؤشر منها : }
$$

أ - الصدق الظاهري Face Validity:

تم التحقق من الصدق الظاهريعن طريق عرض المقياس بصيغته الاولية على متخصص

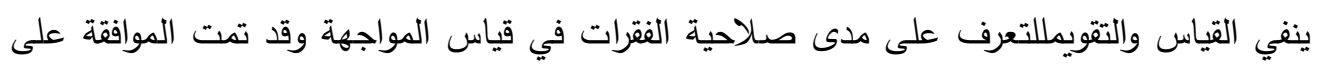

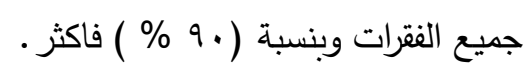

ب - صدق البناء: Construction Validit

تم التحقق من هذا المؤشر عن طريق ابقاء الفقرات ذات العلاقة الدالة احصائيا واستبعاد الفقرات الضعيفة الارتباط ، لذلك يمكن ان تكون معاملات ارتباط الفقرات بالدرجة الكلية والقدرة

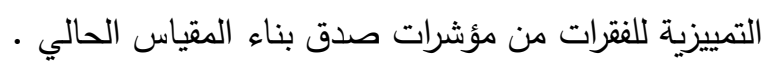
ثبات المقياس : ويعد الثبات احد مؤشرات التحقق من دقة المقياس واتساق فقراته في قياس ما يجب قياسه

• (Crocker \&Algine, 1986: 125) وقد تم حساب الثبات بطريقة : طريقة الفاكرونباخ (Alpha Cronbach, 1951): طبقت معادلة ( الفاكرونباخ ) على درجات افراد العينة البالخ عددهم ( . . ب) طالب وطالبة

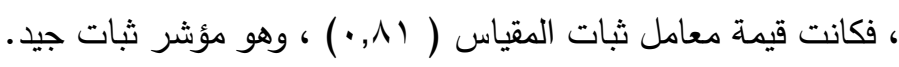

المعايير Norms :

ان تفسير الدرجة التي يحصل عليها الافراد تعد المرحلة الاخيرة من مراحل تقنين المقياس ،

فمن الضروري الحصول على مؤشرات تفسر الدرجة على المقياس وتوضح مصادر الخطا فيها ل

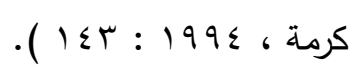

ولكي نتمكن من تقويم اداء الطالب لا بد ان يكون ذلك في ضوء معايير معينة اذ تسمح هذه

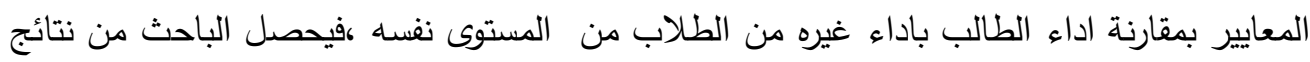

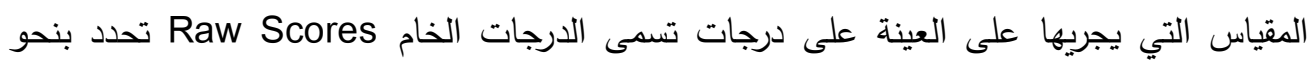


العـــــــد السابع والثلاثون

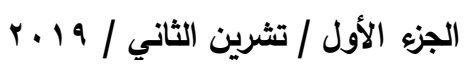

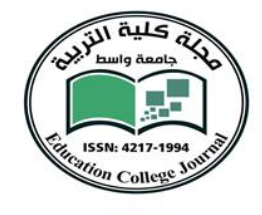

جامعة واسط

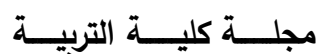

معين مقدار ما يستحقه الطالب على المقياس ، ولا نستطيع ان نقارن من خلالها درجة الطالب بنفسه في مقاييس اخرى ومقارنته بغيره من الطلاب ، وذلك لاختلاف ظروف اجراء المقياس وطبيعة المادة

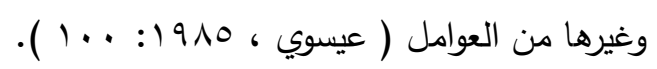

لذا يلجأ الباحثون الى استخدام قوانين رياضية وطرائق احصائية تمكنهم من اجراء المقارنات سواء بين درجات الفرد وزملائه ام بين درجات الفرد نفسه على مقاييس مختلفة (سمارة واخرون، (10:919 (1) ).

وهنالك انواع متعددة من المعايير التي تشتق للاختبارات والمقاييس النفسية هي معايير

(نسب الذكاء ومعايير العمر ومعايير الفروق الدراسية والمعايير المئينية ومعايير الدرجة المعيارية المعدلة والمعيار التساعي ) ولكل منها مميزاته وعيوبه ، فكثيرا ما تستخدم معايير نسب الذكاء ومعايير العمر مع اختبارات الذكاء والقدرات العقلية ، اما المعايير المئينية فهي تستخدم في معظم

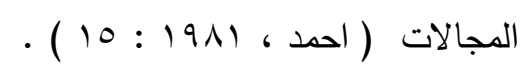

لذلك اعتمدت الباحثة في البحث الحالي في استخراجها لمعايير المقياس على المئينات .

\section{عينة اشتقاق المعايير :}

لقد اتبعت الباحثة الاسلوب المرحلي العشوائي في اختيار العينة البالغة ( . عـ) طالب وطالبة. من كلية التربية جامعة واسط اذ اتبعت الخطوات الاتية :

ا- تم اختيار عينة بناء المعايير من اربع مراحل دراسية من كلية التربية وبشكل عشوائي

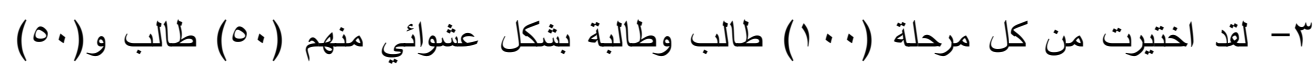

طالبة (7) يوضتح ذلك الجدول (7)

حجم عينة اشتقاق المعاييربحسب المرحلة والجنس

\begin{tabular}{|c|c|c|c|}
\hline العدد الكلي & اناث & ذ ذكور & المرحلة \\
\hline $1 \cdots$ & 0. & 0. & المرحلة الاولى \\
\hline $1 \cdots$ & 0. & 0. & المرحلة الثانية \\
\hline $1 \ldots$ & 0. & 0. & المرحلة الثالثة \\
\hline $1 \cdots$ & 0. & 0. & المرحلة الرابعة \\
\hline$\varepsilon \ldots$ & $r \ldots$ & $r .$. & المجموع \\
\hline
\end{tabular}


العـــــــد السابع والثلاثون

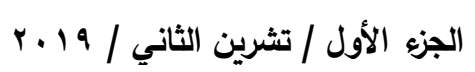

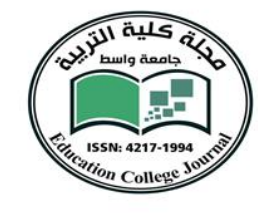

جامعة واسط

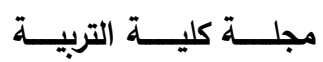

تصحيع المقياس :

لقد تم تصحيح اجابات الطلبة عن فقرات المقياس البالغة ( r م ) فقرة ، وبحسب التدرج الرباعي المعتمد وتكون الدرجة الخام للطلبة بجمع اجابتهم على فقرات المقياس.

المعالجات الاحصائية للمتغيرات المرتبطة بالمعايير :

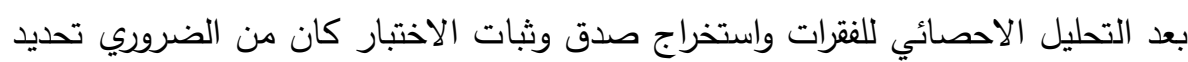

الفروق الاحصائية ما بين متغير الجنس ( ذكور ، اناث ) ومتغير المرحلة (اولى ، ثانية ، ثالثة ، رابعة) وذلك لمعرفة دلالة الفروق ولتحقيق ذلك استخدمت الباحثة الاختبار التائي العينتين مستقلتين لمعرفة دلالة الفرق بين الذكور والاناث ، المرحلة وكانت النتائج كما يأتي. 1- ان الفرق بين درجات الطلاب ( الذكور ) والطالبات ( الاناث ) بدلالة احصائية عند مستوى لئ

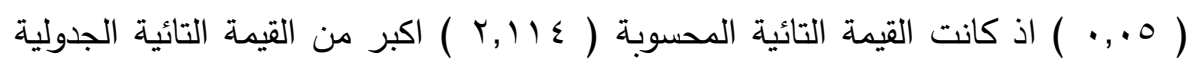
البالغة (7 9 , 1 ) ، وهذا يعني انهما لاينتميان الى مجتمع إحصائي واحد لذلك تحسب معايير خاصة للذكور والاخرى للاناث الجدول (v).

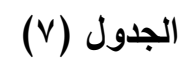

نتائج الاختبار التائي لعينتين مستقلتين لارجات الأكور والإناث

\begin{tabular}{|c|c|c|c|c|}
\hline القيمة $\quad$ المسوبة & الانحراف & المتوبط & عدد الأفراد & المتغيرات \\
\hline \multirow{2}{*}{$r, 1) \leq$} & Ir, Tr & or,rV. & $r .$. & ذكور \\
\hline & & $\varepsilon q, \vee \varepsilon$. & $r \ldots$ & إناث \\
\hline
\end{tabular}

ץ- كان الفرق بين درجات طلبة المراحل الدراسية الأربعة بدلالة إحصائية عند مستوى (0... )

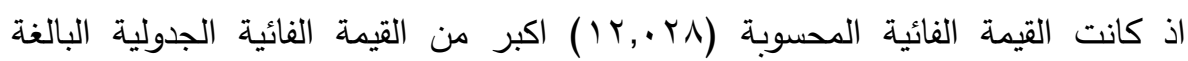

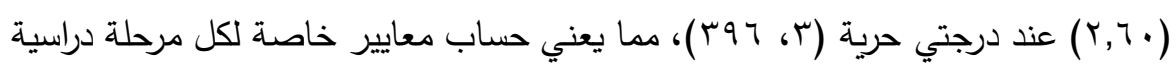


العـــــــد السابع والثلاثون

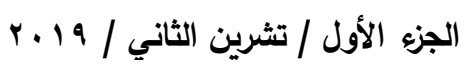

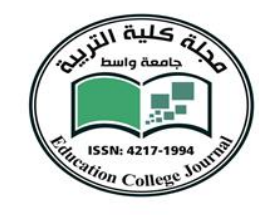

جامعة واسط

مجلـــة كليـــــة التربيــــة

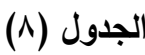

نتائج تحليل التباين الأحادي لالالة الفرق بين درجات المراحل الأربعة

\begin{tabular}{|c|c|c|c|c|}
\hline النسبة الفائية & $\begin{array}{r}\text { S.M } \\
\text { S.M }\end{array}$ & d.f درجة الحرية & $\begin{array}{r}\text { S.S } \\
\text { S.S }\end{array}$ & مصدر التباين \\
\hline \multirow{3}{*}{$\mid r, \cdot r \Lambda$} & IVrr,Aiv & $r$ & $\Delta r+1, \leqslant 0$. & بين المجموعات \\
\hline & $1 \leq \varepsilon, 10$. & एव & ov.Ar,r . & داخل المجموعات \\
\hline & & rqq & TrYAs, Vq. & الكلي \\
\hline
\end{tabular}

وبعد الانتهاء من اجراءات تطبيق المقياس على افراد عينة اشتقاق المعايير وحساب الدرجات الكلية استخرجت

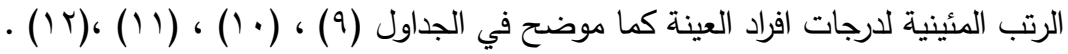

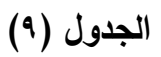

معايير الرتب المئينية لارجات الأكور والإناث ( المرحلة الأولى)

\begin{tabular}{|c|c|c|c|c|c|}
\hline & \multicolumn{2}{|c|}{ إناث مرحلة أولى } & & \multicolumn{2}{|c|}{ ذكور مرحلة اولى } \\
\hline الرتبة المئينية & التكرار & الإرجة & الرتبة المئينية & التكرار & الارجة الخام \\
\hline 0 & 0 & rr & $r$ & $r$ & r. \\
\hline ir & $r$ & r & 7 & $r$ & r \\
\hline 19 & $r$ & ro & $1 Y$ & $\varepsilon$ & ro \\
\hline$r V$ & 0 & rv & YY & 7 & $r v$ \\
\hline rq & $\varepsilon$ & $\varepsilon$. & $r$ & 0 & $\varepsilon$. \\
\hline$\varepsilon r$ & $r$ & $\varepsilon r$ & $\leqslant r$ & $\varepsilon$ & $\varepsilon r$ \\
\hline or & 7 & $\leqslant 7$ & 01 & 0 & $\leqslant 7$ \\
\hline 71 & $r$ & 0 . & $0 Q$ & $r$ & 0 . \\
\hline IV & $r$ & or & 79 & $\varepsilon$ & or \\
\hline$V \Sigma$ & $\varepsilon$ & $\Delta \wedge$ & VY & $r$ & $\Delta \wedge$ \\
\hline Ar & $\varepsilon$ & 7. & $V V$ & $r$ & 7. \\
\hline$\wedge \wedge$ & $r$ & 70 & $\Lambda \varepsilon$ & $\varepsilon$ & 10 \\
\hline$q \pi$ & $r$ & 79 & $q r$ & $\varepsilon$ & 71 \\
\hline $9 \wedge$ & $r$ & 71 & $9 \wedge$ & $r$ & $v$. \\
\hline
\end{tabular}


العـــــد السابع والثلاثون

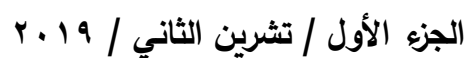

جامعة واسط

مجلـــة كليـــة التربيــة

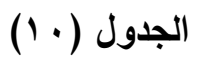

معايير الرتب المئينية لارجات الأكور والإناث ( المرحلة الثانية)

\begin{tabular}{|c|c|c|c|c|c|}
\hline & \multicolumn{2}{|c|}{ إناث مرحلةثانية } & \multicolumn{3}{|c|}{ ذكور مرحلة ثانية } \\
\hline الرتبة المئينية & 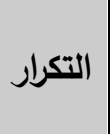 & الارجة & الرئبنية & التكرار & الارجة \\
\hline$\varepsilon$ & $\varepsilon$ & $r$. & $r$ & r & r \\
\hline r & 。 & Tr & 9 & 0 & r \\
\hline rt & $\varepsilon$ & $r \varepsilon$ & iv & r & ro \\
\hline r & $\circ$ & rv & $r \varepsilon$ & $\varepsilon$ & rᄉ \\
\hline$\varepsilon$ & $\varepsilon$ & $\varepsilon$. & ז & 0 & $\varepsilon$. \\
\hline$\varepsilon \vee$ & $r$ & $\varepsilon r$ & $\varepsilon r$ & $\varepsilon$ & $\varepsilon r$ \\
\hline 07 & $\varepsilon$ & $\leq 7$ & or & 7 & $\leq 0$ \\
\hline$T \varepsilon$ & $\varepsilon$ & 0. & 71 & r & or \\
\hline$\vee \cdot$ & $r$ & 00 & TV & r & 00 \\
\hline vo & $r$ & 01 & $v r$ & r & $0 \wedge$ \\
\hline$\wedge$ & $r$ & 7. & VA & r & 7. \\
\hline M & $\varepsilon$ & 70 & Ar & r & 70 \\
\hline $9 \varepsilon$ & r & $\uparrow \wedge$ & 9. & $\varepsilon$ & $v$. \\
\hline 91 & r & $\vee \cdot$ & $9 \vee$ & r & VY \\
\hline
\end{tabular}


العــــــد السابع والثلاثون

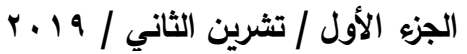

جامعة واسط

مجلـــة كليـــة التربيــة

(11) - الجدول

معايير الرتب المئينية لارجات الذكور والإناث ( المرحلة الثالثة)

\begin{tabular}{|c|c|c|c|c|c|}
\hline & \multicolumn{2}{|c|}{ إناث مرحلتثالثة } & & \multicolumn{2}{|c|}{ ذكور مرحلة ثالثة } \\
\hline الرتبة المئينية & التكرار & الخام & المئينية & الت التكرار & الخام \\
\hline$r$ & r & ro & r & r & o \\
\hline 1. & $\varepsilon$ & rᄉ & v & r & rᄉ \\
\hline 19 & 0 & $\varepsilon$. & $1 \varepsilon$ & $\varepsilon$ & $\varepsilon$. \\
\hline rq & 0 & $\varepsilon r$ & Y) & r & $\varepsilon r$ \\
\hline$r V$ & $r$ & $\leqslant \varepsilon$ & TV & $r$ & $\leq 0$ \\
\hline$\varepsilon \varepsilon$ & $\varepsilon$ & $\leq 0$ & $r \varepsilon$ & $\varepsilon$ & $\leqslant \wedge$ \\
\hline 01 & $r$ & $\leqslant \wedge$ & $\varepsilon r$ & 0 & 0. \\
\hline 01 & $\varepsilon$ & 0 . & 0. & r & 00 \\
\hline $7 \varepsilon$ & $r$ & 00 & 00 & $r$ & 01 \\
\hline$\vee \cdot$ & $\varepsilon$ & $0 \wedge$ & 71 & r & 7. \\
\hline VV & $r$ & 7. & 79 & 0 & Tr \\
\hline 人 & r & Tr & VV & r & 70 \\
\hline 19 & $r$ & 70 & 10 & 0 & 71 \\
\hline $9 \varepsilon$ & r & 71 & 94 & r & $V Y$ \\
\hline 91 & $r$ & $V T$ & 91 & r & VI \\
\hline
\end{tabular}


العــــــد السابع والثلاثون

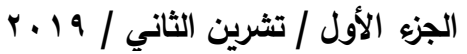

جامعة واسط

مجلـــة كليـــة التربيــة

الجدول (r)

معايير الرتب المئينية لارجات الذكور والإناث ( المرحلة الرابعة)

\begin{tabular}{|c|c|c|c|c|c|}
\hline \multicolumn{3}{|c|}{ إناث مرحلترابعة } & \multicolumn{3}{|c|}{ ذكور مرحلة رابعة } \\
\hline الرتبة المئينية & التكرار & الخام & الرئبة & 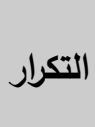 & الخام \\
\hline r & r & ro & r & r & rᄉ \\
\hline v & r & щᄉ & 7 & r & $\varepsilon$. \\
\hline 10 & 0 & $\varepsilon r$ & 11 & $r$ & $\varepsilon r$ \\
\hline$r \varepsilon$ & $\varepsilon$ & $\leqslant 0$ & 17 & r & $\leqslant 0$ \\
\hline r & r & $\varepsilon \wedge$ & r) & r & $\varepsilon \wedge$ \\
\hline rv & r & 0. & rV & r & 0. \\
\hline$\varepsilon \varepsilon$ & $\varepsilon$ & or & $r \varepsilon$ & $\varepsilon$ & or \\
\hline or & $\varepsilon$ & 00 & $\varepsilon 1$ & r & 00 \\
\hline 09 & $r$ & $0 \wedge$ & $\leqslant \wedge$ & $\varepsilon$ & $0 \wedge$ \\
\hline 70 & r & 7. & 00 & r & 7. \\
\hline VI & $r$ & $T Y$ & Tr & 0 & $T Y$ \\
\hline V7 & r & 70 & vi & $r$ & 70 \\
\hline 10 & 0 & 71 & $\wedge$. & 7 & $7 \wedge$ \\
\hline 9. & r & $v$. & 19 & r & VY \\
\hline $9 \leqslant$ & r & VY & $9 \varepsilon$ & r & VI \\
\hline $9 \wedge$ & r & $\vee \wedge$ & 91 & $r$ & ᄉ. \\
\hline
\end{tabular}


العـــــــد السابع وإلثلاثون

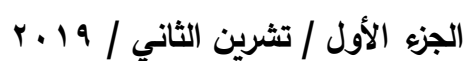

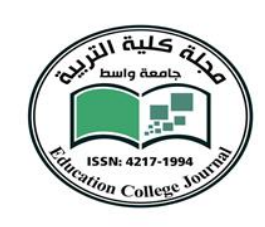

جامعة واسط

\section{وصف الاختبار بصورته النهائية :}

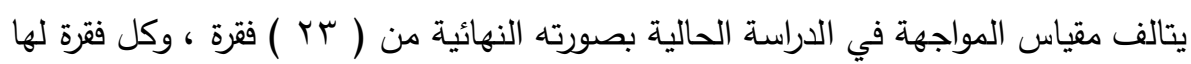
البدائل (انا لا اقوم بهذا ابدا ، انا اقوم بهذا بنحو اقل ، اقوم بهذا بكمية متوسطة ، اقوم بهذا كثيرا )

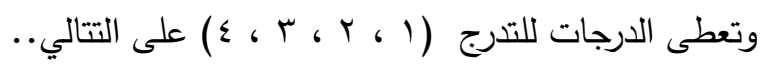
ويتم حساب الدرجة الكلية للمقياس من خلال جمع الدرجات التي يحصل عليها المستجيب لكل فقرة من فقرات المقياس ، لذلك تكون اعلى درجة يمكن ان يحصل عليها المستجيب ( r و ) درجة وهي تمثل اعلى الدرجات واقل درجة يحصل عليها المستجيب هي (TM ) وهي تمثل ادنى درجة كلية على الى المقياس ، وبذلك فان المتوسط النظري للاختبار يكون (ov,0 ) درجة . . التوصيات :

1- امكانية استخدام المقياس المقنن في البحث الحالي في التعرف على المواجهة لدى طلبة المرحلة الجامعية .

ץ- الاعتماد على الندوات التثقيفية لرفع مستوى المواجهة عند الطلبة ץ- الاهتمام بتحديث مناهج التعلم للمرحلة الجامعية لزيادة مواجهة الطلبة لكافة التحديات. المقترحات :

تطويرا للبحث الحالي وإكمالا له تقترح الباحثة اجراء دراسات لاحقة له مثل : ו- اجراء دراسة تكثف عن علاقة المواجهة بمتغيرات اخرى r- تقنين مقياس المواجهة على عينات اخرى. r- بناء برنامج تدريبي لتمية اسلوب المواجهة عند الطلبة باستخدام المقياس الحالي. 
العـــــــد السابع وإلثلاثون

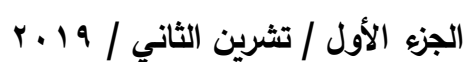

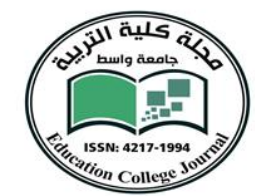

جامعة واسط

مجلـــة كليـــــة التربيــــة

\section{المصادر :}

-احمد ، محمد عبد السلام (1919) القياس النفسي وإلتربوي، طب ا، المجلد الاول، القاهرة، مكتبة النهضة المصرية.

-ابو حطب ، فؤاد (9VV) (19Vوث في تقنين الاختبارات النفسية، المجلد الاول، القاهرة مكتبة الانجلو المصرية.

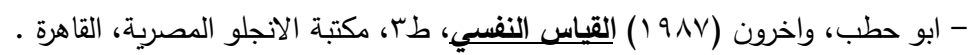

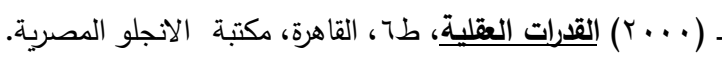

-احمد، محمد عبد السلام (.997) (لقياس النفسي والتربوي، المجلد الاول القاهرة، مكتبة الانجلو المصرية. - اسعد، ميخائيل، ابراهيم (191 1) القياس النفسي، دمثق مطبعة الجمهورية.

- بحر العلوم، حازم محمد (9Av) بناء معايير وطنية لاحتبار فلانجان لتصنيف الاستعدادات بالمهن الهنسية،

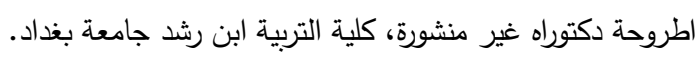

-الحلو، بثينة منصور (1990 ) قوة تحمل الثخصية وأساليب التعامل مع ضغوط الحياة ،( أطروحة دكتوراه غير

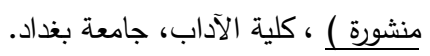
- جلال، سعد (910) القياس النفسي (المقاييس والاختبارات)، القاهرة، دار الفكر العربي. -خلف طاهر عيسى (9 1 (1) يناء اختبار جمعي للأكاء للمرحلة المتوسطة في العلق، اطروحة دكتوراه غير منشوره، جامعة بغداد، كلية التربية، ابن رشد.

- سمارة، عزيز واخرون (919 (19) مبادئ القياس والتقويم في التربية، عمان، دار النكر للنشر والتوزيع. -السيد ، فؤاد البهي (979 19) الأكاء، طب، القاهرة، دار الفكر العربي.

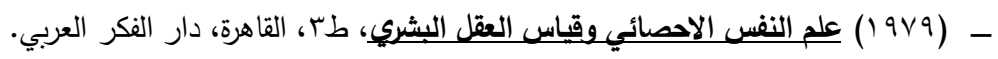

-الصغير ، رياض محمد عبدالله ( ( . ب) تكيف بطارية الاستعدادات الفارقية على طلبة مراكز التريب المهني في

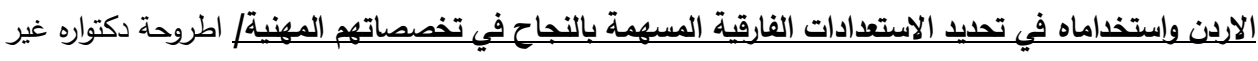
منشوره، جامعة بغداد كلية التربية ، ابن رشد.

-عبد الخالق، احمد محمد (ب99 ( ) بعض الشروط المنهجية والضوابط الاخلاقية في استخدام الاختبارات النفسية، مجلة التقويم والقياس النفسي والتربوي، العدد r. -عبد الرحمن، سعد (r/911) القياس النفسي، الكويت، مكتبة الفلاح. . عبد الرحمن ، سعد (991 ()) القياس النفسي، الكويت، مكتبة الفلاح. 
العـــــــد السابع والثلاثون

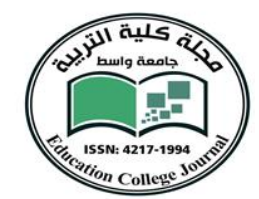

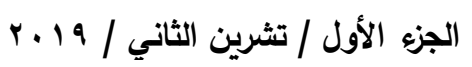

جامعة واسط

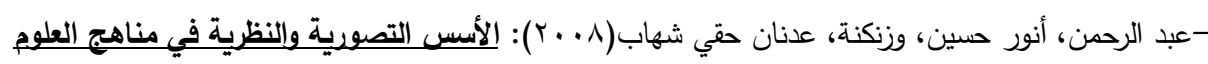

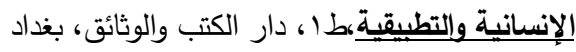

-عبد الرحمن، انور حسين واخرون ( • 99 ) القياس والتقويم، بغداد، دار الحكمة.

- عبد الفتاح، مهدي، والسلمان، عبد العالي محمد (†1911) محاولة تقنين اختبار المصفوفات المتتابعة/المستوى

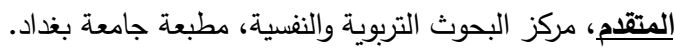

-عبد الوهاب، فائزة محمد سعيد (r/91 (1) تقنين وتكييف اختبارات القدرة على التفكير الابتكار على طلبة كلية العلوم في

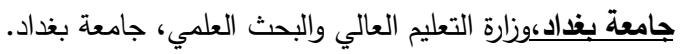

- عبد الوهاب، فائزة محدد سعيد (r/911) تقنين وتكييف اختبارات القرة على التفكير الابتكار على طلبة كلية العلوم في

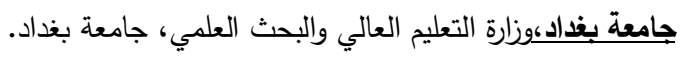

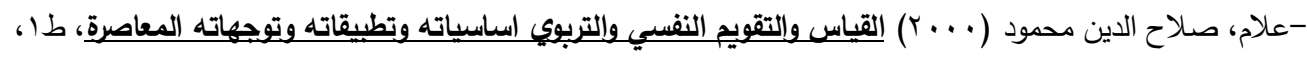
القاهرة، دار الفكر العببي.

-عودة، احمد سليمان (910 (190) القياس والتقويم في العملية التدريسية، الاردن، المطبعة الوطنية.

-عودة ، أحمد سليمان والخليلي، خليل يوسف (911 (1): الإحصاء للباحث في التربية والعلوم الإنسانية، دار الفكر للتوزيع والنشر ، عمان.

-عوض الله، محمد عبد الرحيم محمد ( . . . مقارنة بين اسلوب انموذج راش والطريقة التقليدية في بناء اختبارات الذكاء باستخدام محك التنبؤ بالتحصيل الدراسي، اطروحة دكتوراه غير منشورة جامعة بغداد، كلية التربية ابن رشد. -عيسوي، عبد الرحمن محمد (910 (1) القياس التجريبي في علم النفس والتربية، القاهرة، دار المعارف الجامعية. -عيسوي، عبد الرحمن سعد (919 ()) الاحصاء السايكلوحي والتطبيقي، بيروت، دار النهضة.

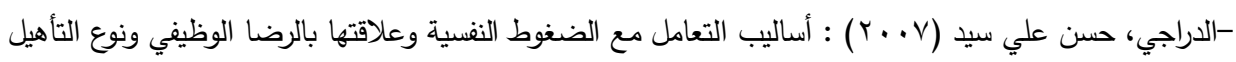
وأنماط يونك للثخصية لدى معلمي المدارس. -فرج، صفوت (•1911) القياس النفسي، طا، القاهرة، دار الفكر العربي. - كاظم، علي مهدي (؟ 99 (1) بناء مقياس مقنن لسمات الثخصية لطلبة المرحلة الاعدادية في العرلق، (اطروحة

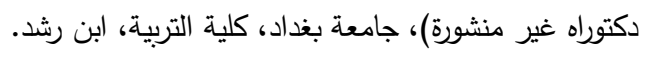


العـــــــد السابع والثثلاثون

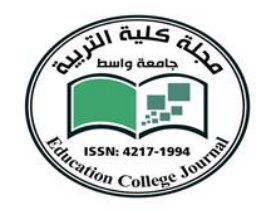

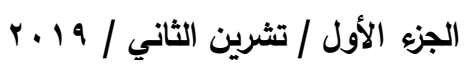

جامعة واسط

مجلـــة كليـــــة التربيــــة

-الكبيسي، كامل ثامر (9AVV) بناء وتقنين مقياس لحساب الثخصية ذات الاولوية القبول في الكليات العكرية لاى

طلبة الصف السادس الاعدادي في العراق، (اطروحة دكتوراه غير منشورة)، جامعة بغداد، كلية التربية، ابن رشد.

كرمة، صفاء طارق حبيب (؟9 99 (1) بناء مقياس مقنن للذكاء الاجتماعي لاى طلبة الجامعة، رسالة ماجستير غير. منشورة، كلية التربية ابن رشد جامعة بغداد.

-كرمة، صفاء طارق حبيب (1991) بناء بطارية اختبارات الاستعدادات الجامعية لاى الطلبة خريجي المرحلة

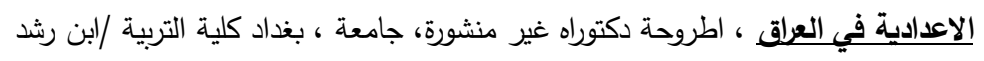

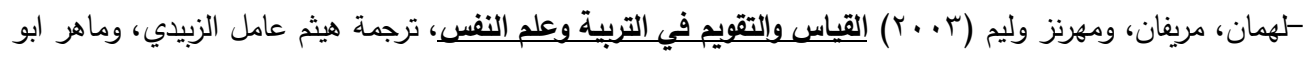

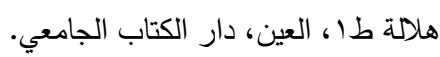

-المصري، محمد عبد المجيد (999 199) اثر اتجاه الفقرة واسلوب صياغتها في الخصائص السيكومترية لمقاييس الثخصية وحسب مستوى الصحة النفسية للمجيب، اطروحة دكتوراه غير منشورة، جامعة بغداد، كلية التربية، ابن رشد.

-مليكة، لويس كامل واخرون (·9V (19) الاختبار السايكولوجي اطار حضاري - اجتماعي في مليكة لويس كامل، قراءات في علم النفس الاجتماعي في البلاد العربية، المجلد الثاني.

1. Anastasi, A. (1988): Psychological Testing, $6^{\text {th }}$ ed. New York, Macmillan Publishing Co. Inc.

2. -Adkins, D.C. (1974) Test Construction. Ohio, Abell \& Howel Company.

3. Lemke .E. and Wireme. W. ( 1979 ) Principles of Psychological Measurement . Chicago .

4.Crocker, L. \&Algine, J. (1986) Introduction to Classical and Modern Test Theory. $2^{\text {nd }}$. New York. Holt, Rinehart \& Winston.

5-Bechtoldt, H.P (1959): Construct validity, A critique, American Psychologist. Vol 14. No.5 619-629.

6-Brawn. F. G. (1976): Principles of Education and Psychological Testing, $2^{\text {nd }}$ ed, New York: Holt Print hart and Winston.

7-Brennan, R.L. (1972): A Generalized Upper-Lower Item Discrimination Index.

Educational and Psychological Measurement. Vol. 32. 209-303.

8-D'Agostion, R. B \& Cureton, E.E (1975): The 27 percent Rule Revisited. Educational and Psychological Measurement. Vol. 35, No1, 47-50. 9-Dubois, P,H. (1962): $\underline{\text { A note on }}$ the Compution of Biserial R in Item Validation-Psycholmetrika. Vol7, No4, 143-146. 1.-Eble, K,L. (1972) Essentials of Education Measurement, $2^{\text {nd }}$ Erylood: California. -Frceman. F.S. (1962): Theory and Practice of Psychological testing, $3^{\text {rd }}$ ed, New York, Holt, Rinehart and Winston.

-Folkman.S.\&Lazarus .R.S(1980):Ananalysis of coping in amiddle aged community sample. Journal of Health and Social Behavior.21,PP:219-239 . 


$$
\begin{aligned}
& \text { العـــــــد السابع والثلاثون }
\end{aligned}
$$

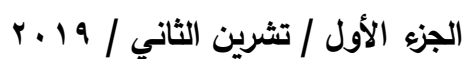

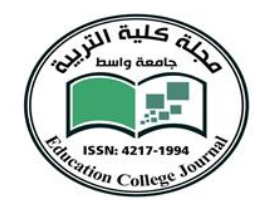

-Feshbach, Seymour \&Weiner, Bernard (1991): Personality (3rd ed.), Los Angeles, D.C. Heath and Company

-Ghiselli, E.E. Campbell. J.P \& Zedeck, S (1981) Measurement Theory for the Behavioral

Science, San Francisco. W.H- Frehman \& Company. -Guilford-J.P (1954) Psycometric Methods, $2^{\text {nd }}$ ed. New York, McGraw-Hill Book

$$
\text { Company. Inc. }
$$

-Gulliksen, H. (1967): Theory Mental Test, New York. John Wiley \& Sons. Inc.

-Gronlund- (1976) Measurement and Evaluation in teaching, $3^{\text {rd }}$ ed-New York,

\section{Macmillan Publishing Co, Inc.}

-Guttman, L.L. (1956): The Test-Retest reliability of Qualitative Data, Psychometric Vol. 11. No. 3 80-89.

-Helmstadter, G-C (1966): Principles of Psychological Measurement. London, Mcthum \& Co. Ltd.

-Holzinger.K.J. (1962): The Applicability of the spearman-Brown Formula of the Measurement of reliability, Journal of Educational Psychology, Vol, 16, No2, 300-303.

-Henrysoon, S. (1971): Gathering, Analyzing and using data on test Items. In Robert.

L. Thorondik. Educational Measurement, $2^{\text {nd }}$ ed, Washington, American council on Education.

-Jenkins, J. G (1966) Validity for What? Journal of consulting psychology. Vol 10. No4, 93-98.

-Jones, L.V. (1971): The Nature of measurement, in Robert L. Thorndik. Education Measurement Washington, American council on education, 335355.

-Kaitz, H.B (1965): A Note on Reliability, Psychometrics, Vol 19. No.3, 127-131.

-Magnusson, D (1967): Testing theory, London, Addison - Wesley Publishing Company.

Oosterhof, A-C (1976): Similarity of various Item Discrimination Indices- Journal of Educational Measurement. Vol. 13, No2, 145-150.

-Pidgeon. D. \& Yates. A. (1974): An Introduction to Educational Measurement. London, Rutledge \& Kegan Paul.

-Pearlin, L. I., \&Schooler, C. (1978). The structure of coping. Journal of health and social behavior, 2-21.

- $\quad$ Schmaling, Karen B. \&Sher, Tamara Goldman (2000): The Psychology of Couples and Illness: Theory, Research,andpractice,u.s.a,American psycho logical associ-a tion

Wade, Carole and Tavris, Carole (2003): Psychology (7th ed.), New Jersey, Pearson Education, Inc. 